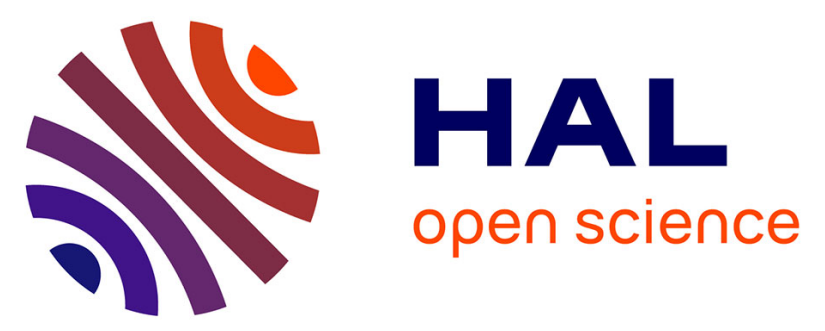

\title{
Microsatellite markers and cytoplasmic sequences reveal contrasting pattern of spatial genetic structure in the red algae species complex Mazzaella laminarioides
}

\author{
Marie-Laure Guillemin, Myriam Valero, Kennia Morales Collio, Ramona \\ Pinochet Sanchez, Miguel Henríquez Espinosa, Andrea X. Silva
}

\section{To cite this version:}

Marie-Laure Guillemin, Myriam Valero, Kennia Morales Collio, Ramona Pinochet Sanchez, Miguel Henríquez Espinosa, et al.. Microsatellite markers and cytoplasmic sequences reveal contrasting pattern of spatial genetic structure in the red algae species complex Mazzaella laminarioides. Journal of Phycology, 2016, 10.1111/jpy.12440 . hal-01333426

\author{
HAL Id: hal-01333426 \\ https://hal.science/hal-01333426
}

Submitted on 17 Jun 2016

HAL is a multi-disciplinary open access archive for the deposit and dissemination of scientific research documents, whether they are published or not. The documents may come from teaching and research institutions in France or abroad, or from public or private research centers.
L'archive ouverte pluridisciplinaire HAL, est destinée au dépôt et à la diffusion de documents scientifiques de niveau recherche, publiés ou non, émanant des établissements d'enseignement et de recherche français ou étrangers, des laboratoires publics ou privés. 
MICROSATELLITE MARKERS AND CYTOPLASMIC SEQUENCES REVEAL

2 CONTRASTING PATTERN OF SPATIAL GENETIC STRUCTURE IN THE RED

3 ALGAE SPECIES COMPLEX MAZZAELLA LAMINARIOIDES

4

5 Marie-Laure Guillemin

6 Instituto de Ciencias Ambientales y Evolutivas, Facultad de Ciencias, Universidad

7 Austral de Chile, Casilla 567, Valdivia, Chile.

8 CNRS, Sorbonne Universités, UPMC University Paris VI, UMI 3614, Evolutionary

9 Biology and Ecology of Algae, Station Biologique de Roscoff, CS 90074, Place G.

10 Tessier, 296888 Roscoff, France.

11 Email: marielaure.guillemin@gmail.com

12 Phone: +56 0632221703

13 Myriam Valero

14 CNRS, Sorbonne Universités, UPMC University Paris VI, UMI 3614, Evolutionary 15 Biology and Ecology of Algae, Station Biologique de Roscoff, CS 90074, Place G.

16 Tessier, 296888 Roscoff, France.

17 Kennia Morales Collio

18 Instituto de Ciencias Ambientales y Evolutivas, Facultad de Ciencias, Universidad

19 Austral de Chile, Casilla 567, Valdivia, Chile.

20 Ramona Pinochet Sanchez

21 Instituto de Ciencias Ambientales y Evolutivas, Facultad de Ciencias, Universidad

22 Austral de Chile, Casilla 567, Valdivia, Chile.

23 Miguel Henríquez Espinosa

24 Instituto de Ciencias Ambientales y Evolutivas, Facultad de Ciencias, Universidad

25 Austral de Chile, Casilla 567, Valdivia, Chile.

26 Andrea X. Silva

27 AUSTRAL-omics, Facultad de Ciencias, Universidad Austral de Chile, Casilla 567, 28 Valdivia, Chile.

29

30 Running Title: Genetic discordance in Mazzaella laminarioides 
32 Abstract: Mazzaella laminarioides (Bory) is a common haploid-diploid red alga that

33 forms dense beds. This alga has a wide distribution range, covering $3,500 \mathrm{~km}$ of the

34 Chilean coast, but is restricted to high rocky intertidal zones. Recently, the existence of

35 three highly divergent genetic lineages was demonstrated for this taxon, and two

36 cytoplasmic markers were used to determine that these lineages are distributed in strict

37 parapatry. Here, using 454 next-generation sequencing, we developed polymorphic

38 microsatellite loci that cross amplify in all three cytoplasmic lineages. Six sites (i.e. two

39 sites within each lineage) were analyzed using nine microsatellite loci. Our work shows

40 that, although substantial cytoplasmic differentiation occurs within M. laminarioides, the

41 microsatellite loci did not retrieved three nuclear genetic clusters as expected. Indeed,

42 while the northernmost and southernmost cytoplasmic lineages form two strongly

43 divergent nuclear groups characterized by diagnostic alleles, the third cytoplasmic

44 lineage did not form a third nuclear independent group. It is possible that inter-lineage

45 gene exchange has occurred, particularly at sites along the contact zone between the

46 different cytoplasmic lineages. This nuclear-cytoplasmic incongruence in $M$.

47 laminarioides could be explained by incomplete lineage sorting of the nuclear genes or

48 asymmetric introgressive hybridization between the lineages. Finally, highly significant

49 heterozygote deficiencies (suggesting occurrence of intergametophytic selfing) were

50 observed in the three small northernmost sites while the large southernmost sites

51 generally approached panmixia.

53 Keywords: Chile, gene flow, intergametophytic selfing, microsatellites, Rhodophyta, 54 species complex 
56 List of abbreviations:

57 COI, cytochrome c oxidase sub-unit1

58 cpDNA, chloroplast DNA

59 ENSO, El Niño Southern Oscillation

60 HRMA, high resolution melting analysis

61 LD, linkage disequilibrium

62 mtDNA, mitochondrial DNA

63 PCA, principal component analysis

64 RAPD, random amplified polymorphic DNA

65 rbcL, large subunit of the ribulose-1,5-bisphosphate carboxylase/oxygenase enzyme

66

67 Introduction

68 The Chilean coast is mostly linear from north to south and characterized by very dynamic

69 and regionalized tectonic, oceanographic and climatic processes (Thiel et al. 2007,

70 Guillemin et al. 2015). These coastal and oceanic features have led to contrasted pattern

71 of marine biodiversity distributed over three main biogeographic regions (Camus 2001,

72 Thiel et al. 2007). The particularities of the Chilean coast have stimulated a strong 
73 interest in deciphering the phylogeographic patterns of the marine realm in this region

74 and studies have accumulated rapidly during the last five years (see for review in

75 invertebrates: Haye et al. 2014 and in seaweeds: Guillemin et al. 2015). More specifically,

76 these two reviews report the use of molecular markers in species that cross the

77 biogeographic boundaries to compare concordance among phylogeographic and

78 biogeographic breaks. In seaweeds, based on the occurrence of divergent mitochondrial

79 lineages, several putative cryptic species were uncovered along the Chilean coast: in

80 Lessonia (Tellier et al. 2009), Durvillaea (Fraser et al. 2009), Adenocystis (Fraser et al.

81 2013), Mazzaella (Montecinos et al. 2012) and Nothogenia (Lindstrom et al. 2015). Most

82 of these studies were only based on the analysis of the cytoplasmic genomic compartment,

83 except for Lessonia in which comparison of divergence at nuclear and cytoplasmic

84 markers supported the same pattern (Tellier et al. 2009). Furthermore, in this last case,

85 nuclear microsatellites markers were used to demonstrate that the two cryptic species did

86 not share any alleles and were, thus, reproductively isolated (Tellier et al. 2011).

$87 \quad$ However, conflicting geographic patterns between mitochondrial and nuclear

88 genetic markers have been observed when demographic asymmetries produce dissimilar

89 movement in the two marker types or when different selective pressures affect the

90 mitochondrial and the nuclear genome (Toews and Brelsford 2012). For example, in the

91 barnacle Notochthamalus scabrosus, Zakas et al. (2014) reported that the nuclear genome

92 homogeneity throughout the central and northern regions of Chile contrasted with the

93 strong mitochondrial divergence pattern described previously (Zakas et al. 2009). They

94 concluded that there is little reason to treat the two mitochondrial groups as distinct

95 species. In contrast with invertebrates, dispersal is generally limited to less than a few 
96 kilometers in seaweed and such pattern of nuclear homogeneity along the Chilean coast is

97 not expected in those organisms (Kinlan and Gaines, 2003). It is thus interesting to test

98 for algae cryptic species, which were defined on the basis of divergent cytoplasmic

99 lineages, if their pattern of nuclear genetic structure is congruent with their cytoplasmic

100 divergence.

101 Mazzaella laminarioides is a haploid-diploid rocky shore species that forms dense

102 beds in high intertidal zones. This carrageenophyte is an economically important resource

103 in Chile and is harvested from natural populations by small fishing communities

104 (Buschmann et al. 2001). M. laminarioides is non-buoyant and is considered to be a poor

105 disperser (Faugeron et al. 2001). The species distribution range encompasses a high

106 variety of environmental conditions as it covers $3,500 \mathrm{~km}\left(28-56^{\circ} \mathrm{S}\right)$ of Chilean coastline

107 (Thiel et al. 2007). Using two cytoplasmic genes (COI, mitochondrial and $r b c \mathrm{~L}$,

108 chloroplast), Montecinos et al. (2012) revealed strong genetic structure within $M$.

109 laminarioides with the existence of three divergent genetic lineages distributed along the

110 Chilean coast. They reported the presence of a northern lineage from $28^{\circ} \mathrm{S}$ to $32^{\circ} \mathrm{S}$, a

111 central lineage from $34^{\circ} \mathrm{S}$ to $37^{\circ} \mathrm{S}$, and a southern lineage from $39^{\circ} \mathrm{S}$ to $56^{\circ} \mathrm{S}$. Guillemin

112 et al. (2015) confirmed that the three lineages are distributed in strict parapatry with sharp

113 phylogeographic breaks of a few kilometers in width. However, the presence of

114 reproductive barriers has not been tested between these three lineages.

115 In M. laminarioides, the three cytoplasmic lineages were separated for the $r b c \mathrm{~L}$

116 by 0.6 to $1.0 \%$ divergence and for COI by 2.6 to $7.8 \%$ divergence and no cytoplasmic

117 incongruence was observed (Montecinos et al. 2012). In red algae, where both plastid and

118 mitochondria DNA maternal inheritance have been observed (Zuccarello and West 2011), 
119 cytoplasmic incongruence have generally been related to events of interspecific

120 hybridization (Destombe et al. 2010). These results suggest that strong reproductive

121 barriers probably evolved between the three lineages of M. laminarioides limiting

122 hybridization even in the contact zones. Indeed, in the Rhodophyta, laboratory crosses

123 between phylogenetic species have generally revealed complete reproductive

124 incompatibility that correlates with cytoplasmic genetic distances (Brodie and Zuccarello

125 2006, Zuccarello and West 2011 and reference therein). In the three species complex

126 thoroughly studied (i.e. Spyridia, Bostrychia, and Mastocarpus), the experiments showed

127 that strains sharing the same chloroplastic haplotypes (rubisco spacer) were always fully

128 compatible while strains differing by only 0.6 to $2.1 \%$ were not able to be crossed

129 (Zuccarello and West 2002, Zuccarello and West 2003, Zuccarello et al. 2005).

130 We can predict that, in agreement with plastid and mitochondrial information, the

131 nuclear genome should present strong genetic discontinuities with no or very limited gene

132 flow among the three cytoplasmic lineages of M. laminarioides. In this context, we

133 developed nine microsatellite markers for the red alga M. laminarioides in order to

134 confirm the existence of nuclear genetic structure and to test for potential hybridization

135 between the three previously described parapatric cytoplasmic lineages.

137 Material and Methods

138 Development of microsatellite markers - In order to construct the 454 libraries, a single

139 haploid (i.e. a female gametophyte) specimen was used as the source of DNA for each

140 three cytoplasmic lineages of M. laminarioides. Samples from Fray Jorge

$141\left(30^{\circ} 40^{\prime} \mathrm{S} / 71^{\circ} 42^{\prime} \mathrm{W}\right)$, Constitución $\left(35^{\circ} 19^{\prime} \mathrm{S} / 72^{\circ} 26^{\prime} \mathrm{W}\right)$ and Chiloe $\left(41^{\circ} 52^{\prime} \mathrm{S} / 71^{\circ} 01^{\prime} \mathrm{W}\right)$ were 
142 used for the northern, central and southern lineage respectively (Montecinos et al. 2012).

143 DNA was extracted following the protocol described by Saunders (1993); slight

144 modifications were made according to Faugeron et al. (2001). PicoGreen ${ }^{\mathrm{TM}}$ fluorescence

145 enhancement (Ahn et al. 1996) was used to test DNA quality and quantity. DNA

146 sequencing was performed using a 454 GS Junior Titanium Series (Roche) at the

147 AUSTRAL-omics Core-Facilities. Briefly, each DNA sample was tagged using different

148 multiplex identifiers (MIDs). DNA library fragments were captured onto beads and

149 clonally amplified within individual emulsion droplets. Amplified fragments from all

150 three lineages were evenly mixed and sequenced on 3 PicoTiterPlates. Library

151 preparation, amplification, and sequencing were carried out following the manufacturer

152 protocols (Roche Diagnostics Corporation, Branford, Connecticut USA). The assembly

153 of the reads was performed using the MIRA (Chevreux et al. 1999) and CAP3 (Huang

154 and Madan 1999) software programs. In order to determine which contigs correspond to

155 nuclear sequences, nucleotide BLAST (http://blast.ncbi.nlm.nih.gov/Blast.cgi) searches

156 were performed using the complete mitochondrial genome of Chondrus crispus (25.836

157 bp NC_001677) and using the complete plastid genome of C. crispus (180.086 bp,

158 HF562234). Moreover, in order to identified loci sequenced in more than one of our three

159454 libraries, we performed nucleotide BLAST searches between the three cytoplasmic

160 lineages contig files.

161 Nucleotide repeats from di- to hexa-nucleotides were identified using

162 MSATCOMMANDER (Faircloth 2008). Generally, the BLAST searches between the

163 three cytoplasmic lineages contig files show that the same microsatellite locus have been

164 sequenced in more than one of our three 454 libraries (see Table S1). For microsatellite 
165 loci present in more than one of our three 454 libraries, alignment between the different

166 cytoplasmic lineages were performed in GENEIOUS R6 for each locus (Biomatters Ltd.).

167 For 30 loci with a high number of repetitions (at least 7 repetitions) and long flanking

168 regions located in the nuclear contigs, primers pairs were designed using GENEIOUS R6

169 (Biomatters Ltd.). When the same microsatellite locus was encountered in more than one

170454 library (see Table S1) the primer pairs were designed within the more conserved part

171 of the flanking region. All loci for which alignment between the different cytoplasmic

172 lineages were performed showed clear homologies in their flanking regions.

173 Following primer design, PCR cross amplification of all three lineages was

174 performed; for this, three individuals from Fray Jorge, three individuals from

175 Constitución, and three individuals from Chiloe were used. For the 20 loci that amplified

176 successfully in all three lineages, high resolution melting analysis (HRMA, Mackay et al.

177 2008) was used to make a preliminary assessment of variability. For each lineage, three

178 sites were tested: Fray Jorge, Puerto Obscuro, and Maitencillo for the northern lineage;

179 Topocalma, Constitución, and Concepción for the central lineage; and Pucatrihue, Chiloe,

180 and Punta Arenas for the southern lineage. Fifteen haploid individuals from each site

181 were used. The COI regions of all of the haploid samples were previously sequenced in

182 the study of Montecinos et al. (2012). The HRMA analyses showed that twelve loci were

183 polymorphic for M. laminarioides.

184 Genotyping - The twelve polymorphic loci were used to genotype 96 diploid individuals

185 sampled from Caleta Sauce (SAU, N=16), Mina Talca (MIT, N=18), Montemar (MTM,

$186 \mathrm{~N}=16$ ), Lebu (LEB, N=16), Pilolcura (PIL, N=16) and Melinka (MLK, N=14) (see Figure

187 1A). The samples from SAU and MIT represent the northern cytoplasmic lineage, the 
188 samples from MTM and LEB represent the central cytoplasmic lineage, and the samples

189 from PIL and MLK represent the southern cytoplasmic lineage (Figure 1A). Cytoplasmic

190 markers sequences are not available for all the samples genotyped with microsatellites.

191 However, since the geographic distribution of the three different cytoplasmic clades

192 (Montecinos et al., 2012) was shown to be strictly parapatric (i.e. each region

193 corresponding to a single cytoplasmic clade with no mixture and no overlapping of

194 distribution of haplotypes between regions), geographical origin of the individuals was

195 considered as a good proxy for cytoplasmic clades' assignation. Direct observations of

196 the reproductive organs (tetrads) in the field were used to select only diploid

197 tetrasporophytes in each localities sampled.

$198 \quad$ PCR reactions were performed in $12.5 \mu \mathrm{L}$ reactions containing $50 \mathrm{ng}$ of template

199 DNA, 1X PCR buffer, $0.2 \mathrm{mM}$ dNTPs, $0.5 \mu \mathrm{M}$ of each primer and $1 \mathrm{U}$ Top Taq DNA

200 polymerase (Qiagen, Valencia, CA, USA). The concentrations of BSA and $\mathrm{MgCl}_{2}$ are

201 shown in Table S1. The PCR program consisted of an initial denaturation of $3 \mathrm{~min}$ at

$20294^{\circ} \mathrm{C}, 35$ cycles each with $94^{\circ} \mathrm{C}$ for $40 \mathrm{~s}, 40 \mathrm{~s}$ at optimized $\mathrm{Ta}$ (Table S1), and $30 \mathrm{~s}$ at

$20372{ }^{\circ} \mathrm{C}$, and with a final extension of $7 \mathrm{~min}$ at $72{ }^{\circ} \mathrm{C}$. PCR products were sent to the

204 Servicio de Secuenciacion Depto. Ecologia, Pontificia Universidad Catolica de Chile,

205 Chile, for fragment analyses. Fragments were separated using an Applied Biosystems

206 3130XL Genetic Analyzer (Life Technologies Corporation).

207 Statistical analyses - Allele size was determined with the GENEMARKER software

208 (SoftGenetics, State Collage, PA, USA). Prior to analyses, the frequency of null alleles

209 was estimated for each locus using MICRO-CHECKER (Van Oosterhout et al. 2004;

210 Brookfield equation 2, Brookfield 1996). Linkage disequilibrium at all locus pairs was 
211 assessed using FSTAT version 2.9.3.2 (Goudet 2001). Statistical significance of LD was

212 calculated based on 1000 permutations using Bonferonni correction for $\alpha=0.05$. Single

213 and multilocus estimates of genetic diversity were calculated as the mean number of

214 alleles per locus ( $\mathrm{Na})$, expected heterozygosity ( $\mathrm{He}$, sensus Nei 1978) and observed

215 heterozygosity (Ho) using GENETIX 4.05 (Belkhir et al. 1996-2004). Allele frequencies

216 were calculated for each study site at each locus and plotted using the R-package

217 StandArich (available at http://www.ualg.pt/ccmar/maree/software.php, F. Alberto,

218 University of Algarve, Faro, Portugal). Single and multilocus estimates of deviation from

219 random mating $\left(F_{\mathrm{IS}}\right)$ were calculated according to Weir and Cockerham (1984),

220 significance was determined by running 1000 permutations of alleles among individuals

221 within sites using GENETIX 4.05 (Belkhir et al. 1996-2004). Genetic differentiation

222 among sites was analyzed by estimating $F_{\mathrm{ST}}(\theta)$ (Weir and Cockerham 1984);

223 significance of $F_{\text {ST }}$ values was assessed by running 1000 permutations using GENETIX

2244.05 (Belkhir et al. 1996-2004). Principal component analysis (PCA) was conducted

225 using PCAGEN (Goudet 1999) to visualize pairwise differentiation among sites $\left(F_{\mathrm{ST}}\right)$;

2261,000 randomizations of genotypes were used to determine axis significance. Bayesian

227 inference was implemented in STRUCTURE v. 2.2 (Pritchard et al. 2000) in order to

228 detect potential signs of hybridization and/or introgression between lineages. We used the

229 admixture model and allowed for correlated allele frequencies between sites. A range of

230 clusters (K), from 1 to 10 were tested. Each run, replicated 20 times, consisted of 400000

231 iterations after a "burn-in" of 200000. To infer which K best fit the data, we applied the

$232 \mathrm{ad}$ hoc $\Delta \mathrm{K}$ statistic developed by Evanno et al. (2005). The results from STRUCTURE

233 were then compared to those of INSTRUCT (Gao et al. 2007), which relaxes 
234 STRUCTURE's assumption of Hardy-Weinberg equilibrium as it was designed for

235 species with significant self-fertilization. INSTRUCT was run with the parameters "-K 3

236 -v 2 -x 0 -w 0 -j 20000 -e 0 -f 0 -L 9 -N 96 -p 2 -u 600000 -b 200000 -t 10 -c 20 -sl 0.95 -

237 g 1 -r 20000 -ik 1 -kv 110 -df 1 -af 0 -mm 2.0e9" with K ranging from 1 to 10 (i.e. -kv).

238 For both STRUCTURE and INSTRUCT analyses, combined results of the independent

239 runs were obtained using the greedy algorithm with100000 random input orders in

240 CLUMMP (Jakobsson and Rosenberg 2007) before exporting the results to DISTRUCT

241 (Rosenberg 2004) for viewing.

$243 \quad$ Results

244 We obtained 172872 reads for the northern lineage, 238901 reads for the central lineage

245 and 111945 reads for the southern lineage (average length: $436 \mathrm{bp}$ ). In total, 1091

246 microsatellite inserts were observed for the northern lineage, 1805 for the central lineage

247 and 667 for the southern lineage (see Table S2 for more details). Most of the

248 microsatellites recovered were di- (87.3\%) and trinucleotides $(10.8 \%)$ while larger

249 repeated motifs were rare $(0.9 \%$ tetranucleotides and $0.9 \%$ pentanucleotides) (Table S2).

250 Of the 12 polymorphic loci developed during this study (Table S1, Table S3),

251 three loci (Ml_39C37, Ml_106C1748 and Ml_106C203) were not retained for population

252 genetic analyses. The locus Ml_39C37 was not retained because it presented strong and

253 significant linkage disequilibrium with locus M1_106C32. The locus M1_106C1748 failed

254 to amplify in 33 of the 96 DNA samples $(\mathrm{NI} / \mathrm{n}=0.6$, Table S3) and the locus

255 Ml_106C203 presented a very low level of polymorphism. Indeed, M1_106C203 was 
256 fixed for all sites from the northern and southern lineage and only two alleles were

257 observed over the whole dataset (Table S3).

$258 \quad$ For the nine loci selected (i.e. shaded in grey in Table S3), observed

259 heterozygosities ranged from 0.11 to 0.57 while expected heterozygosities ranged from

2600.59 to 0.87 for the whole data set (Table S3). The number of alleles encountered in each

261 site varied from 1 to 10 while the average number of alleles per locus was 3.11 ( $\mathrm{SE}=$

262 1.69) (Table S3). Three loci were moderately polymorphic (4-6 alleles) and six were

263 highly variable (9-26 alleles). The frequency of null alleles was significant for five loci

264 in some of the sites studied (Ml_106C75 in four sites; Ml_106C32 in two sites; and

265 Ml_39C1451, Ml_39C5118 and Ml_39C4313 in only one site) (Table S3). The estimated

266 frequency of null alleles ranged from 0.12 to 0.36 (Table S3).

$267 \quad F_{\text {IS }}$ values were highly variable among loci and sites. The number of significant

$268 F_{\text {IS }}$ values per locus was only slightly higher in the central lineage $(8 / 16)$ than in the

269 northern (6/15) and southern lineages (6/17) (Table S3). However, the $F_{\text {IS }}$ multilocus

270 estimates (Table 1$)$ show that only LEB and PIL were close to panmixia $\left(F_{\text {IS }}=-0.03\right.$ and

$271-0.07$, respectively). Alternatively, a negative and significant $F_{\text {IS }}$ was encountered for

$272 \operatorname{MLK}\left(F_{\text {IS }}=-0.17\right)$, and positive and significant $F_{\text {IS }}$ values were encountered in the three

273 northern most sites of SAU, MIT and $\mathrm{MTM}\left(F_{\mathrm{IS}}=0.16,0.14\right.$ and 0.45 , respectively,

274 Table 1). Similar results were obtained when corrections for null alleles were made

275 (Table 1).

276 Allele size distributions generally overlapped between cytoplasmic lineages when

277 all six sites were taken into account (Figure S1). However, for three of the 12 loci

278 (M1_106_C462, Ml_39_C69 and Ml_106_C32, Figure S1), allele distributions were 
279 totally disjoint between the southernmost and northernmost cytoplasmic clades (i.e. these

280 three loci are diagnostic for each of the two clades). In addition, a clear gradient of

281 variation in allele size with respect to latitude was observed for those three loci (Figure

282 S1). For the loci Ml_39C69 and Ml_106C462, shorter alleles were encountered in sites

283 from the northern lineage while for the locus Ml_106C32 shorter alleles were observed in

284 sites from the southern lineage (Figure S1). Sites belonging to the central lineage had

285 alleles of intermediate size; the MTM site presented allele sizes that were more similar to

286 the northern lineage while the LEB site presented allele sizes was more similar to the

287 southern lineage (Figure S1). For the Ml_106_C462, M1_39_C69 and M1_106_C32 loci,

288 the LEB site presented $27.3 \%$ of private alleles, $54.5 \%$ of alleles that were shared with

289 the two sites representing the southern cytoplasmic clade (PIL and MLK) and 9.1\% of

290 alleles that were shared with the two sites representing the northern cytoplasmic clade

291 (SAU and MIT) (Figure S1). For the same three loci, the MTM site presented $76.9 \%$ of

292 private alleles, $7.7 \%$ of alleles that were shared with the two sites representing the

293 southern cytoplasmic clade and $23.1 \%$ of alleles that were shared with the two sites

294 representing the northern cytoplasmic clade (Figure S1).

The PCA summarized the information given by the nine loci (Figure 1B) and

296 showed results that were congruent with the allele size distribution results. The first two

297 axes explained $39.4 \%$ ( $\mathrm{PC} 1)$ and $26.0 \%$ (PC2) of the total genetic differentiation $\left(F_{\mathrm{ST}}\right)$

298 (Figure 1B). The first axis separated sites of the northern lineage (SAU and MIT) from all

299 other lineages (MTM, LEB, PIL and MLK) while the second axis discriminated sites of

300 the central lineage from those of the southern lineage (Figure 1B). However, the MTM

301 site holds a unique position in the PCA and was located in-between the group composed 
302 of the three southernmost sites (LEB, PIL and MLK) and the two sites from the northern

303 lineage along the first axis and was separated from the other five study sites along the

304 second axis (Figure 1B). All pairwise $F_{\text {ST }}$ multilocus values were significantly different

305 from zero and ranged from 0.253 (between PIL and MLK, both from the southern

306 lineage) to 0.581 (between PIL and SAU, northern vs southern lineage differentiation,

307 Table S4). Similar results were found when using the dataset after corrections for null

308 alleles were made (pairwise $F_{\mathrm{ST}}$ ranges from 0.249 to 0.572 , Table S4).

309 Results from the clustering analysis performed with both STRUCTURE and

310 INSTRUCT, revealed that the posterior probability of the data increased steadily from K

$311=1$ to $\mathrm{K}=6$ while the curves dropped after $\mathrm{K}=7$ (Figure $\mathrm{S} 2$ and $\mathrm{S} 3$ ). The $\Delta \mathrm{K}$ method of

312 Evanno et al. (Evanno et al. 2005) clearly shows that both K2 and K6 clusters are the

313 optimal numbers of clusters in our study (Figure S2). Contrary to our expectations, the

314 number of nuclear genetic clusters retrieved was two or even six but definitely not three

315 as predicted with organelle sequences. For $\mathrm{K}=6$, both STRUCTURE and INSTRUCT

316 identified the same 6 clusters each corresponding to a different sampling site

317 (STRUCTURE: Figure 2; INSTRUCT: Figure S3). Almost all individuals from the same

318 site had similar membership coefficients and, overall, a very low level of admixture was

319 observed (Figure 2, K6 and Figure S3). This result indicated that differentiation occurs

320 between all of the sampling sites. The Bayesian clustering assignment in STRUCTURE

321 for $\mathrm{K}=2$ shows that all individuals from the northern lineage (i.e. SAU and MIT)

322 grouped together while the three southernmost sites belonging to the central and southern

323 lineages (i.e. LEB, PIL and MLK) formed another cluster. However, clustering of the

324 MTM individuals to one or the other cluster did vary among the different STRUCTURE 
325 runs. Eleven of the 20 runs (Figure 2, K2 upper graph) assigned all MTM individuals to

326 the northern genetic cluster while individuals from MTM were assigned to the southern

327 genetic cluster for the other 9 runs (Figure 2, K2 lower graph). Only central lineage

328 cytoplasmic COI sequences were observed (M-L. Guillemin, unpublished data) in this

329 site located only 13 kilometres from the contact zone with the northern lineage (Figure

$330 \quad 1 \mathrm{~A})$.

332 Discussion

333 In this study, nine variable microsatellite markers have been developed for $M$.

334 laminarioides using 454 next-generation sequencing. Recently, this method has been

335 used successfully to develop microsatellite markers for various eukaryotic species (see

336 the review by Meglécz et al. 2012) including some red algae (Couceiro et al. 2011a,

337 Pardo et al. 2014, Ayres-Ostrock et al. 2015). Repetitive sequences were encountered in

338 less than $0.7 \%$ of the M. laminarioides reads. In other red algae (Couceiro et al. 2011a,

339 Pardo et al. 2014, Ayres-Ostrock et al. 2015) and in corrals (Ruiz-Ramos and Baums

340 2014), the percentage of repetitive sequences is generally much higher and ranges from

$341 \quad 1.3 \%$ in the candelabrum coral Eunicea flexuosa to $11.6 \%$ in the coralline alga

342 Phymatolithon calcareum. This scarcity of repetitive sequences clearly reduced our

343 capacity to develop microsatellites markers for M. laminarioides where less than $0.03 \%$

344 of the reads yielded microsatellites with sufficient motif repetitions (i.e. > 7). Considering

345 that the main aim of this study was to investigate the pattern of gene flow across the $33^{\circ} \mathrm{S}$

346 and the $38^{\circ} \mathrm{S}$ transition zones, only loci that amplified in all three lineages were selected.

347 A reported drawback of cross-amplifying loci is the high probability of generating an 
348 uneven amplification of the target loci, which could result from defective primers or

349 deviations from optimal amplification conditions, between different taxa (Selkoe and

350 Toonen 2006). In our study, five loci revealed a moderate to high frequency of null

351 alleles in some sites. In M. laminarioides, no clear differences were observed between the

$352 F_{\text {IS }}$ and the $F_{\text {ST }}$ estimates calculated using the uncorrected or corrected datasets. As such,

353 the $F_{\text {IS }}$ and $F_{\text {ST }}$ values obtained in our study, even if null alleles are potentially present,

354 can be used to infer biological processes in this species.

$355 \quad$ The results found here only partially supported the previously defined $M$.

356 laminarioides lineages based on cytoplasmic markers (Montecinos et al. 2012). Indeed,

357 contrary to our expectations, the number of main nuclear genetic clusters retrieved by

358 STRUCTURE was two and not three as predicted with organelle sequences. Based on the

359 nuclear marker data, the two northernmost sites (SAU and MIT) that correspond to the

360 northern cytoplasmic lineage and the two southernmost sites (PIL and MLK) that

361 correspond to the southern cytoplasmic lineage formed two differentiated groups. The

362 presence of several unique, high frequency diagnostic alleles supports the existence of a

363 long-term divergence between these two lineages. On the other hand and contrary to the

364 previous results found using cytoplasmic markers (Montecinos et al. 2012), the sites from

365 the central cytoplasmic lineage (MTM and LEB) do not represent a third well-separated

366 group according to nuclear microsatellites. While LEB clearly grouped with sites of the

367 southern cytoplasmic lineage, the position of MTM stays unclear. Indeed, MTM appeared

368 highly differentiated from the other five sites sampled in the PCA. However, shared

369 alleles with sites that correspond to both the northern and southern cytoplasmic lineages

370 were observed in MTM and the site was not assigned to a third main nuclear genetic 
371 cluster in the STRUCTURE analyses but actually shifted between the northern and the

372 southern genetic cluster, depending on the STRUCTURE run for K2. The discordance

373 observed between the present study, based on nuclear markers, and the previously

374 published work based on cytoplasmic markers could simply be explained by incomplete

375 lineage sorting of the nuclear genes. Due to the differences in effective population size

376 between the maternally and the bi-parentally inherited genomes (nuclear effective

377 population size is approximately four times greater than that of the mitochondria and

378 chloroplast) lineage sorting is expected to be faster for organelle genomes than for the

379 nucleus. It is thus expected to observe greater genetic differentiation using mtDNA and

380 cpDNA genes than when using nuclear genes (see Zink and Barrowclough 2008 for a

381 review). Discordance between genomes can also arise if there are differences in the way

382 selection acts on the non-recombinant cytoplasmic genomes as compared to the nuclear

383 genome; or when past and / or present gene flow took / takes place between lineages

384 (Toews and Brelsford 2012). In their study, Montecinos et al. (2012) recognized that

385 cytoplasmic markers showed shallower divergence between the central and southern

386 linages than between the northern lineage and the central/southern clade. Accordingly,

387 complete reproductive barriers may not have yet evolved between the more recently

388 diverging central and southern linages; this suggests that contemporary gene flow might

389 still connect the three southernmost sites of LEB, PIL, and MLK. Moreover, asymmetric

390 introgressive hybridization in the past could also have lead to the incongruence pattern

391 observed in LEB. In algae, such nuclear / cytoplasmic incongruences were observed in

392 various species and interpreted as footprints of hybridization (Destombe et al. 2010,

393 Hoarau et al. 2015) or past introgression (Neiva et al. 2010, Hoarau et al. 2015). In 
394 contrast, the pattern observed for MTM, the other central cytoplasmic lineage site, does

395 not fit this hypothesis of asymmetric introgression. MTM was highly differentiated from

396 both the northern sites (SAU and MIT, $\sim 230 \mathrm{~km}$ away, $F_{\mathrm{ST}}>0.5$ ) and the central and

397 southern sites (LEB, PIL and MLK, $\sim 550 \mathrm{~km}$ away, $F_{\mathrm{ST}}>0.4$ ). Individuals from this site

398 exhibited a high number of private alleles with intermediate sizes between the sizes of the

399 diagnostic alleles of the two nuclear groups. The MTM site is located only 13 kilometers

400 away from the contact zone with the northern lineage. However, only one individual of

401 MTM was determined to be a possible hybrid. This individual correspond to a genotype

402 assigned mostly to the MTM cluster but for which the secondary cluster of MIT

403 represents more than $5 \%$ of the genome in both the STRUCTURE and the INSTRUCT

404 clustering results for K6 (see Figure 2 and S3). The genetic composition of this individual

405 was more consistent with an old hybridization event followed by consecutive backcrosses

406 than with a recent hybridization event. This result reinforce the idea that gene leakage is

407 reduced even at the $33^{\circ} \mathrm{S}$ transition zone margin.

408 It is hypothesized that progressive, multiple genome-wide changes accumulated

409 by drift or selection between two gene pools will lead to the build-up of reproductive

410 isolation over time (Nosil and Feder 2012). Hybridization and introgression between two

411 diverging taxa should then diminish with time of divergence. At first sight, this supports

412 the idea that, while reaching a determined threshold of genetic distance, all taxa in a

413 taxonomic group will reach complete reproductive isolation and could then be recognized

414 as a biological species. The existence of such a correlation is the key argument provided

415 to support the creation of a universal threshold to define species using DNA barcoding

416 methods (the $1 \%$ threshold for the COI mitochondrial marker as mentioned in BOLD, 
417 Ratnasingham and Hebert 2007). However, the timeframe of speciation is strongly

418 influenced by factors such as drift, opportunities for ecological adaptation, and intrinsic

419 rates of mutations (Sobel et al., 2010), and these factors have been shown to vary

420 depending on the taxa being studied (Dufresnes et al. 2014 and 2015). For COI in red

421 algae, genetic distances between 4.5 to $13.6 \%$ were reported between species of the same

422 genus (Saunders 2005, Clarkston and Saunders 2010) but sister species of Mazzaella that

423 diverged by less than $1.2 \%$ were also reported (Saunders 2005). In M. laminarioides, the

424 genetic distance between the three COI-defined cytoplasmic lineages were well within

425 the red algae threshold to delimit species in this genus (2.6 to $7.8 \%$, Montecinos et al.

426 2012). Our work shows that, although substantial mtDNA and cpDNA differentiation

427 occurs within M. laminarioides (Montecinos et al. 2012), this does not necessarily

428 correlate with the existence of complete reproductive isolation. In this study, as in others

429 focused on recently diverging lineages distributed in parapatry (Colliard et al. 2010,

430 Zarza 2011, Dufresnes et al. 2014 and 2015), cytoplasmic markers and microsatellites did

431 not reveal the same pattern of genetic subdivision. However, due to the low number of

432 sites sampled in our study, the true number of M. laminarioides nuclear genetic groups

433 will remain unresolved until a more detailed sampling is conducted.

434 The very high $F_{\mathrm{ST}}$ estimates (all $\left.>0.24\right)$ obtained in our study suggest that gene

435 flow between the sampled sites is minimal even when sites were previously classified as

436 part of the same nuclear genetic group and cytoplasmic lineage. The retrieval of six

437 clusters, each corresponding to a different sampling site and showing a very low level of

438 admixture, by both STRUCTURE and INSTRUCT, confirm the high differentiation

439 between our six sampling sites. Red algae, that lack long-lived motile gametes, spores, 
440 and floating structures, are ranked among the poorest dispersers when compared to other

441 marine taxa (Kinlan and Gaines 2003). Genetic differentiation has been reported at the

442 scale of kilometres or even meters in these organisms (Faugeron et al. 2001, Zuccarello et

443 al. 2001, Engel et al. 2004, Couceiro et al. 2011b, Krueger-Hadfield et al. 2013). As

444 reported for M. laminarioides by Faugeron et al. (2001) using random amplified

445 polymorphic DNA (RAPD) markers, high and significant genetic structure exists

446 between sites located less than $40 \mathrm{~km}$ apart $\left(F_{\mathrm{ST}}=0.39\right.$ between SAU and MIT). $F_{\mathrm{ST}}$

447 estimates between the three southernmost sites (LEB, PIL and MLK), spanning more

448 than $730 \mathrm{~km}$ of coast, were significant but lower $\left(0.24<F_{\mathrm{ST}}<0.35\right)$ than estimates

449 calculated for the northern sites. Interestingly, the same pattern was reported for the

450 cytoplasmic markers (Montecinos et al. 2012) where genetic structure was much more

451 pronounced in the northern lineage than in the southern lineage. The authors associated

452 the attributed differences between the northern and southern groups to historical

453 demographic differences. They concluded that southern populations of M. laminarioides

454 were strongly affected by Quaternary glaciations that would have caused recent

455 demographic expansion while northern populations would have experienced repeated

456 local extinctions and range fragmentations due to the El Niño Southern Oscillation

457 (ENSO) (Montecinos et al. 2012).

458 These regional differences between the north and the south could also explain the

459 marked differences between the $F_{\text {IS }}$ estimates reported in our study. Highly significant

460 heterozygote deficiencies were observed in the three northernmost site of SAU, MIT and

461 MTM while the sites of LEB and PIL had observed heterozygosities close to random

462 mating. Departure from random mating in the north could be explained by the recurrence 
463 of massive mortality due to ENSO events observed in this region; this would have

464 resulted in patches of small fragmented populations (as reported in algae, Martínez et al.

465 2003). In the site of MTM, located at the edge of the contact zone with the highly

466 divergent northern lineage (Montecinos et al. 2012), selfing (intergametophytic selfing,

467 see Krueger-Hadfield et al. 2015) could limit gene flow and protect parental genotypes

468 from the formation of hybrid progeny (Antonovics 1968). The prominent role of selfing

469 in the emergence of reproductive barriers has been observed in plants (Martin and Willis

470 2007, Matallana et al. 2010), fungi (Gibson et al. 2011) and brown algae (Engel et al.

4712005 , Billard et al. 2010, Hoarau et al. 2015). Small scale sampling within the $33^{\circ} \mathrm{S}$

472 contact zone is needed to both determine the exact role of selfing as a reinforcement

473 mechanism in M. laminarioides and to better characterize the possible mechanisms

474 responsible of the onset and progress of divergence between the northern and

475 central/south lineages.

476 In conclusion, this study revealed discordant pattern of geographic variation

477 between nuclear microsatellite markers and cytoplasmic sequences in the red alga

478 Mazzaella laminarioides. The presence of several diagnostic alleles did support the

479 existence of a long-term divergence between the northernmost and southernmost

480 cytoplasmic lineages. However, the central cytoplasmic lineage did not form a third

481 nuclear independent group and a high number of shared alleles are observed, principally

482 with the southern cytoplasmic lineage. This shared polymorphism may be explained

483 either by retention of ancestral polymorphism or by hyridization between cytoplasmic

484 lineages. The likelihood of shared ancestral polymorphism vs. recurrent gene flow in

485 these closely related parapatric lineages is a question difficult to test but that we cannot 
486 resolve. Indeed, our study reveals intriguing results for the two sites of the central lineage

487 and jointly leads us to ask if MTM (located at the northern limit of the central lineage)

488 could represent a third nuclear group while the pattern observed in LEB (located in the

489 southern part of the central lineage distribution) is mostly due to ancient or recent gene

490 flow with the neighboring southern lineage. A much denser sampling, especially between

491 the $33^{\circ} \mathrm{S}$ and the $38^{\circ} \mathrm{S}$ where the central lineage is located, is needed to better

492 characterize the complex genetic pattern observed in this region. The southern part of the

$493 \quad 33-38^{\circ} \mathrm{S}$ coast forms a mosaic of sandy beaches and rocky coast characterized by rapid

494 changes due to high tectonic activity. Processes, linked to extinction and recolonization,

495 have probably shaped the intertidal algae population of this region leading to complex

496 pattern of genetic differentiation. Nuclear microsatellites clearly show that $M$.

497 laminarioides does not correspond to a single species widely distributed over 3,500km of

498 Chilean coast. These markers rather suggest that one or several speciation processes have

499 probably shaped the present-day patterns of genetic diversity in this species complex.

500 Unraveling the relations between the M. laminarioides taxa should be the goal of future

501 works.

503 Acknowledgements

504 This research was supported by FONDECYT N ${ }^{\circ} 130797$ (CONICYT, Comisión

505 Nacional de Investigación Científica y Tecnológica, Gobierno de Chile). The authors

506 thank S. Faugeron for the access to Mazzaella laminarioides DNA for the 454-library

507 construction. Additional support came from the International Research Network 
508 “Diversity, Evolution and Biotechnology of Marine Algae” (GDRI N0803). The

509 authors have declared that no competing interests exist.

512 Bibliography

513 Ahn, S. J., Costa, J. \& Emanuel, J. R. 1996. PicoGreen quantitation of DNA:

514 effective evaluation of samples Pre-or post-PCR. Nucleic acids res. 24(13):2623-2625.

515 Ayres-Ostrock, L. M., Mauger, S., Plastino, E. M., Oliveira, M. C., Valero, M. \&

516 Destombe, C. 2015. Development and characterization of microsatellite markers in two

517 agarophyte species, Gracilaria birdiae and Gracilaria caudata (Gracilariaceae,

518 Rhodophyta), using next-generation sequencing. J. Appl. Phycol. 1-10.

519 Belkhir, K., Borsa, P., Chikhi, L., Raufaste, N. \& Bonhomme, F. 1996-2004.

520 Genetix 4.02, Logiciel Sous Windows TM Pour La Génétique Des Populations.

521 Laboratoire Génome, Populations, Interactions, CNRS UMR. 5000, Université de

522 Montpellier II, Montpellier.

523 Billard, E., Serrão, E., Pearson, G., Destombe, C. \& Valero, M. 2010. Fucus

524 vesiculosus and spiralis species complex: a nested model of local adaptation at the shore

525 level. Mar. Ecol. Prog. Ser. 405:163-174.

526 Brodie, J. \& Zuccarello, G. C. 2006. Systematics of the species rich algae: red

527 algal classification, phylogeny and speciation. In Hodkinson, T. R. \& Parnell, J. A. N.

528 [Eds.] Reconstructing the Tree of Life: Taxonomy and Systematics of Species Rich Taxa.

529 The Systematics Associations, Boca Raton, Florida, pp.317-30.

530 Buschmann, A. H., Correa, J. A., Westernmeier, E., Hernandez- Gonzalez, M. D. 
531 C. \& Normabuena, R. 2001. Red algal farming in Chile: a review. Aquaculture 194:203532220.

533 Brookfield, J. F. Y. 1996. A simple new method for estimating null allele

534 frequency from heterozygote deficiency. Mol. Ecol. 5:453-455.

535 Camus, P. A. 2001. Biogeografía marina de Chile continental. Rev. Chil. Hist. Nat.

536 74(3):587-617.

537 Chevreux, B., Wetter, T. \& Suhai, S. 1999. Genome sequence assembly using

538 trace signals and additional sequence information. Compt. Sci. Biol. Proc. Ger. Conf.

539 Bioinformatics 99:45-56.

540 Clarkston, B. E. \& Saunders, G. W. 2010. A comparison of two DNA barcode

541 markers for species discrimination in the red algal family Kallymeniaceae (Gigartinales,

542 Florideophyceae), with a description of Euthora timburtonii sp. nov. Botany 88(2):119-

543131.

544 Colliard, C., Sicilia, A., Turrisi, G. F., Arculeo, M., Perrin, N. \& Stöck, M. 2010.

545 Strong reproductive barriers in a narrow hybrid zone of West-Mediterranean green toads

546 (Bufo viridis subgroup) with Plio-Pleistocene divergence. BMC Evol. Biol. 10(1):232.

547 Couceiro, L., Maneiro, I., Mauger, S., Valero, M., Ruiz, J. M. \& Barreiro, R.

548 2011a. Microsatellite development in Rhodophyta using high - throughput sequence data.

549 J. Phycol. 47(6):1258-1265.

550 Couceiro, L., Maneiro, I., Ruiz, J. M. \& Barreiro, R. 2011b. Multiscale genetic

551 structure of an endangered seaweed Ahnfeltiopsis pusilla (Rhodophyta): implications for

552 its conservation. J. Phycol. 47(2):259-268.

553 Destombe, C., Valero, M. \& Guillemin, M-L. 2010. Delineation of two sibling red 
554 algal species, Gracilaria gracilis and Gracilaria dura (Gracilariales, Rhodophyta), using

555 multiple DNA markers: resurrection of the species G. dura previously described in the 556 northern Atlantic 200 years ago. J. Phycol. 46:720-7.

557 Dufresnes, C., Bonato, L., Novarini, N., Betto-Colliard, C., Perrin, N., \& Stöck,

558 M. 2014. Inferring the degree of incipient speciation in secondary contact zones of

559 closely related lineages of Palearctic green toads (Bufo viridis subgroup). Heredity

560 113(1):9-20.

561 Dufresnes, C., Brelsford, A., Crnobrnja-Isailović, J., Tzankov, N., Lymberakis, P.

$562 \&$ Perrin, N. 2015. Timeframe of speciation inferred from secondary contact zones in the

563 European tree frog radiation (Hyla arborea group). BMC Evol. Biol. 15(1):155.

564 Engel, C. R., Daguin, C. \& Serrão, E. A. 2005. Genetic entities and mating system

565 in hermaphroditic Fucus spiralis and its close dioecious relative F. vesiculosus (Fucaceae,

566 Phaeophyceae). Mol. Ecol. 14:2033-2046.

567 Engel, C. R., Destombe, C. \& Valero, M. 2004. Mating system and gene flow in

568 the red seaweed Gracilaria gracilis: effect of haploid-diploid life history and intertidal

569 rocky shore landscape on finescale genetic structure. Heredity 92:289-298.

570 Evanno, G., Regnaut, S. \& Goudet, J. 2005. Detecting the number of clusters of

571 individuals using the software STRUCTURE: a simulation study. Mol. Ecol.14:26115722620.

573 Faircloth, B. C. 2008. MSATCOMMANDER: detection of microsatellite repeat

574 arrays and automated, locus-specific primer design. Mol. Ecol. Res. 8:92-94.

575 Faugeron S., Valero M., Destombe C., Martínez E. A. \& Correa, J. A. 2001.

576 Hierarchical spatial structure and discriminant analysis of genetic diversity in the red alga 
577 Mazzaella laminarioides (Gigartinales, Rhodophyta). J. Phycol. 37:705-716.

578 Fraser, C. I., Nikula, R., Spencer, H. G. \& Waters, J. M. 2009. Kelp genes reveal

579 effects of subantarctic sea ice during the Last Glacial Maximum. Proc. Natl. Acad. Sci.

580 USA 106:3249-3253.

581 Fraser, C. I., Zuccarello, G. C., Spencer, H. G., Salvatore, L. C., Garcia, G. R., \&

582 Waters, J. M. 2013. Genetic affinities between trans-oceanic populations of non-buoyant

583 macroalgae in the high latitudes of the Southern Hemisphere. PLoS ONE 8(7):e69138.

584 Gao, H. S., Williamson, S. \& Bustamante, C. D. 2007. A Markov chain Monte

585 Carlo approach for joint inference of population structure and inbreeding rates from

586 multilocus genotype data. Genetics 176:1635-1651.

587 Gibson, A. K., Hood, M. E. \& Giraud, T. 2012. Sibling competition arena: selfing

588 and a competition arena can combine to constitute a barrier to gene flow in sympatry.

589 Evolution 66(6):1917-1930.

590 Goudet, J. 1999. [http://www2.unil.ch/popgen/softwares/pcagen.htm].

591 Goudet, J. 2001. FSTAT, a program to estimate and test gene diversities and

592 fixation indices (version 2.9. 3).

593 Guillemin, M-L., Valero, M., Tellier, F., Macaya, E. C., Destombe, C. \&

594 Faugeron, S. 2015. Phylogeography of seaweeds in the South East Pacific: complex 595 evolutionary processes along a latitudinal gradient. In Hu Z-M. \& Fraser, C. [Eds.]

596 Seaweed phylogeography. Springer Verlag, Berlin.

597 Hoarau, G., Coyer, J. A., Giesbers, M. C. W. G., Jueterbock, A., \& Olsen, J. L.

598 2015. Pre-zygotic isolation in the macroalgal genus Fucus from four contact zones

599 spanning 100-10 000 years: a tale of reinforcement? Royal Society Open Science 
2(2):140538.

601 Huang, X. Q. \& Madan, A. 1999. CAP3: a DNA sequence assembly program.

602 Genome Res. 9:868-877.

603 Jakobsson, M. \& Rosenberg, N. A. 2007. CLUMPP: a cluster matching and

604 permutation program for dealing with label switching and multimodality in analysis of

605 population structure. Bioinformatics 23(14):1801-1806.

606 Kinlan, B. P. \& Gaines, S. D. 2003. Propagule dispersal in marine and terrestrial

607 environments: a community perspective. Ecology 84:2007-20.

608 Krueger-Hadfield, S. A., Roze, D., Correa, J. A., Destombe, C. \& Valero, M.

609 2015. O father where art thou? Paternity analyses in a natural population of the haploid-

610 diploid seaweed Chondrus crispus. Heredity 114:185-194.

611 Krueger-Hadfield, S. A., Roze, D., Mauger, S. \& Valero, M. 2013.

612 Intergametophytic selfing and microgeographic genetic structure shape populations of the

613 intertidal red seaweed Chondrus crispus. Mol. Ecol. 22(12):3242-3260.

614 Lindstrom, S. C., Gabrielson, P. W., Hughey, J. R., Macaya, E. C., \& Nelson, W.

615 A. 2015. Sequencing of historic and modern specimens reveals cryptic diversity in

616 Nothogenia (Scinaiaceae, Rhodophyta). Phycologia 54 (2):97-108.

617 Mackay, J. F., Wright, C. D. \& Bonfiglioli, R. G. 2008. A new approach to

618 varietal identification in plants by microsatellite high resolution melting analysis:

619 application to the verification of grapevine and olive cultivars. Plant Methods 4(1):8.

620 Matallana, G., Godinho, M. A. S., Guilherme, F. A. G., Belisario, M., Coser, T. S.

$621 \&$ Wendt, T. 2010. Breeding systems of Bromeliaceae species: evolution of selfing in the

622 context of sympatric occurrence. Plant. Syst. Evol. 289:57-65. 
624 system causes nearly complete reproductive isolation between sympatric Mimulus species.

625 Evolution 61:68-82.

626 Martínez, E. A., Cárdenas, L. \& Pinto, R. 2003. Recovery and genetic diversity of

627 the intertidal kelp Lessonia nigrescens (phaeophyceae) 20 years after el Niño 1982/83.J.

628 Phycol. 39(3):504-508.

629 Meglécz, E., Nève, G., Biffin, E. \& Gardner, M. G. 2012. Breakdown of

630 phylogenetic signal: a survey of microsatellite densities in 454 shotgun sequences from

631154 non model eukaryote species. PLoS One 7(7):e40861.

632 Montecinos, A., Broitman, B. R., Faugeron, S., Haye, P. A., Tellier, F. \&

633 Guillemin, M. L. 2012. Species replacement along a linear coastal habitat:

634 phylogeography and speciation in the red alga Mazzaella laminarioides along the south 635 east pacific. BMC Evol. Biol. 12(1):97.

636 Nei, M. 1978. Estimation of average heterozygosity and genetic distance from a 637 small number of individuals. Genetics 89(3):583-590.

638 Neiva, J., Pearson, G. A., Valero, M. \& Serrao, E. A. 2010. Surfing the wave on a 639 borrowed board: range expansion and spread of introgressed organellar genomes in the 640 seaweed Fucus ceranoides L. Mol. Ecol. 19(21):4812-4822.

641 Nosil, P., \& Feder, J. L. 2012. Genomic divergence during speciation: causes and 642 consequences. Philos. T. Roy. Soc. B 367(1587):332-342.

643 Pardo, C., Peña, V., Bárbara, I., Valero, M. \& Barreiro, R. 2014. Development 644 and multiplexing of the first microsatellite markers in a coralline red alga (Phymatolithon 645 calcareum, Rhodophyta). Phycologia 53(5):474-479. 
647 structure using multilocus genotype data. Genetics 155:945-959.

648 Ratnasingham, S. \& Hebert, P. D. 2007. BOLD: The Barcode of Life Data System

649 (http://www. barcodinglife. org). Mol. Ecol. Notes 7(3):355-364.

650 Rosenberg, N. A. 2004. DISTRUCT: a program for the graphical display of 651 population structure. Mol. Ecol. Notes 4(1):137-138.

652 Ruiz-Ramos, D. V. \& Baums, I. B. 2014. Microsatellite abundance across the 653 Anthozoa and Hydrozoa in the phylum Cnidaria. BMC genomics 15(1):939.

654 Saunders, G. W. 2005. Applying DNA barcoding to red macroalgae: a

655 preliminary appraisal holds promise for future applications. Philos. T. Roy. Soc. B $656360(1462): 1879-1888$.

657 Selkoe, K. A. \& Toonen, R. J. 2006. Microsatellites for ecologists: a practical 658 guide to using and evaluating microsatellite markers. Ecol. Lett. 9(5):615-629.

659 Sobel, J. M., Chen, G. F., Watt, L. R. \& Schemske, D. W. 2010. The biology of 660 speciation. Evolution 64(2):295-315.

661 Tellier, F., Meynard, A. P., Correa, J. A., Faugeron, S., \& Valero, M. 2009.

662 Phylogeographic analyses of the $30^{\circ} \mathrm{S}$ south-east Pacific biogeographic transition zone

663 establish the occurrence of a sharp genetic discontinuity in the kelp Lessonia nigrescens:

664 Vicariance or parapatry? Mol. Phyl. Evol. 53(3):679-693.

665 Tellier, F., Tapia, J., Faugeron, S., Destombe, C. \& Valero, M. 2011. The

666 Lessonia nigrescens species complex (Laminariales, Phaeophyceae) shows strict

667 parapatry and complete reproductive isolation in a secondary contact zone. J. Phycol. $668 \quad 47: 894-903$. 
Thiel, M., Macaya, E. C., Acuña, E., Arntz, W. E., Bastias, H., Brokordt, K., 670 Camus, P. A., Castilla, J. C., Castro, L. R., Cortés, M. et al. 2007. The Humboldt Current 671 System of northern and central Chile. Oceanogr. Mar. Biol. 45:195-344.

672 Toews, D. P. \& Brelsford, A. 2012. The biogeography of mitochondrial and 673 nuclear discordance in animals. Mol. Ecol. 21(16):3907-3930.

674 Van Oosterhout, C., Hutchinson, W. F., Wills, D. P. \& Shipley, P. 2004.

675 MICRO - CHECKER: software for identifying and correcting genotyping errors in 676 microsatellite data. Mol. Ecol. Notes 4(3):535-538.

677 Weir, B. S. \& Cockerham, C. C. 1984. Estimating F-statistics for the analysis of 678 population structure. Evolution 38:1358-1370.

679 Zakas, C., Binford, J., Navarrete, S. A., \& Wares, J. P. 2009. Restricted gene flow 680 in Chilean barnacles reflects an oceanographic and biogeographic transition zone. Mar. 681 Ecol. Prog. Ser. 394:165-177.

682 Zakas, C., Jones, K., \& Wares, J. P. 2014. Homogeneous nuclear background for 683 mitochondrial cline in northern range of Notochthamalus scabrosus. G3: Genes Genomes 684 Genetics 4(2):225-230.

685 Zarza, E., Reynoso, V. H. \& Emerson, B. C. 2011. Discordant patterns of 686 geographic variation between mitochondrial and microsatellite markers in the Mexican 687 black iguana (Ctenosaura pectinata) in a contact zone. J. Biogeo. 38(7):1394-1405. 688 Zink, R. M. \& Barrowclough, G. F. 2008. Mitochondrial DNA under siege in 689 avian phylogeography. Mol. Ecol. 17(9):2107-2121.

690 Zuccarello, G. C., Schidlo, N., Mc Ivor, L. \& Guiry, M. D. 2005. A molecular re691 examination of speciation in the intertidal red alga Mastocarpus stellatus (Gigartinales, 
692 Rhodophyta) in Europe. Eur. J. Phycol. 40:337-44.

693 Zuccarello, G. C. \& West, J. A. 2002. Phylogeography of the Bostrychia

694 calliptera-B. pinnata complex (Rhodomelaceae, Rhodophyta) and divergence rates based

695 on nuclear, mitochondrial and plastid DNA markers. Phycologia 41(1):49-60.

696 Zuccarello, G. C. \& West, J. A. 2003. Multiple cryptic species: molecular

697 diversity and reproductive isolation in the Bostrychia radicans/B. moritziana complex

698 (Rhodomelaceae, Rhodophyta) with focus on North American isolates. J. Phycol.

$69939: 948-959$.

700 Zuccarello, G. C. \& West, J. A. 2011. Insights into evolution and speciation in the

701 red alga Bostrychia: 15 years of research. Algae 26(1):21-32.

702 Zuccarello, G. C., Yeates, P. H., Wright, J. T. \& Bartlett, J. 2001. Population

703 structure and physiological differentiation of haplotypes of Caloglossa leprieurii

704 (Rhodophyta) in a mangrove intertidal zone. J. Phycol. 37:235-44.

705

706

707 
708 Figure 1: Geographic location of the study sites and cytoplasmic clades along the Chilean

709 coast (A) and principal component analysis (PCA) based on mean pairwise $F_{\mathrm{ST}}$ averaged

710 over the nine selected loci (B). In the map, brackets show the cytoplasmic lineages of $M$.

711 laminarioides: "north", "center" and "south". Ellipsoids delineating the three cytoplasmic

712 lineages of Mazzaella laminarioides in the PCA were drawn for better visualization, but

713 they do not have any statistical support.

714 Figure 2: Bayesian analysis using STRUCTURE for the six study sites of Mazzaella

715 laminarioides. Each vertical bar represents a different individual. Each shade represents

716 the proportion of individual genome assigned to each genetic group and * indicates

717 individuals for which a secondary cluster represents more than $5 \%$ of the genome (i.e.

718 admixed individuals). Individuals are ordered from north to south. Results are shown for

719 K2 and K6. For K2, since the 20 independent runs give contrasting results depending on

720 the run, two graphs are presented: one that corresponds to 11 of the 20 runs (upper graph)

721 and the other that corresponds to the remaining 9 of the 20 runs (lower graph). 
Table 1: Multilocus estimates of the number of alleles per locus $(\mathrm{Na})$, expected heterozygosity $(\mathrm{He})$, observed heterozygosity $(\mathrm{Ho})$ and $F_{\text {IS }}$ calculated for the nine selected microsatellite loci. Significant departure from panmixia was tested by running 1,000 permutations of alleles among individuals within sites using GENETIX 4.05 (Belkhir et al. 1996-2004). $F_{\text {IS }}$ values significantly different from zero are shown in bold. Both an uncorrected dataset and a dataset corrected for null alleles (Oosterhout et al. 2004) were used for the calculations. For $\mathrm{Na}, \mathrm{He}$ and $\mathrm{Ho}$, mean and standard deviation computed over the nine loci are noted.

\begin{tabular}{l|l|ccccc}
\hline $\begin{array}{l}\text { Geographic origin of } \\
\text { sampled sites }\end{array}$ & Site & \multicolumn{1}{|c}{$N a$} & $H e$ & $H o$ & $F_{\text {IS }}$ & $p$ \\
\hline $\begin{array}{l}\text { Uncorrected data } \\
\text { set }\end{array}$ & & & & & & \\
\hline $\begin{array}{l}\text { Northern } \\
\text { cytoplasmic lineage }\end{array}$ & SAU & $3.11(1.69)$ & $0.30(0.23)$ & $0.26(0.26)$ & $\mathbf{0 . 1 6}$ & $\mathbf{0 . 0 1 8 0}$ \\
$\begin{array}{l}\text { Central cytoplasmic } \\
\text { lineage }\end{array}$ & MTM & $3.67(2.69)$ & $0.46(0.28)$ & $0.41(0.30)$ & $\mathbf{0 . 1 4}$ & $\mathbf{0 . 0 3 6 0}$ \\
\hline $\begin{array}{l}\text { Southern } \\
\text { cytoplasmic lineage }\end{array}$ & LEB & $3.56(2.35)$ & $0.37(0.28)$ & $0.21(0.23)$ & $\mathbf{0 . 4 5}$ & $\mathbf{0 . 0 0 0 0}$ \\
\hline $\begin{array}{l}\text { Data set corrected } \\
\text { for the presence of } \\
\text { null alleles }\end{array}$ & MLK & $3.11(1.83)$ & $0.48(0.14)$ & $0.51(0.32)$ & -0.03 & 0.3580 \\
\hline $\begin{array}{l}\text { Northern } \\
\text { cytoplasmic lineage }\end{array}$ & SAU & $3.11(1.09)$ & $0.55(0.07)$ & $0.66(0.22)$ & $\mathbf{- 0 . 1 7}$ & $\mathbf{0 . 0 1 1 0}$ \\
\hline $\begin{array}{l}\text { Central cytoplasmic } \\
\text { lineage }\end{array}$ & MIT & $3.67(2.69)$ & $0.47(0.29)$ & $0.42(0.31)$ & $\mathbf{0 . 1 3}$ & $\mathbf{0 . 0 1 8 0}$ \\
\hline $\begin{array}{l}\text { Southern } \\
\text { cytoplasmic lineage }\end{array}$ & $3.56(2.35)$ & $0.40(0.31)$ & $0.24(0.24)$ & $\mathbf{0 . 4 5}$ & $\mathbf{0 . 0 0 0 0}$ \\
\hline & LEB & $3.89(1.83)$ & $0.49(0.14)$ & $0.54(0.29)$ & -0.06 & 0.2100 \\
\hline
\end{tabular}




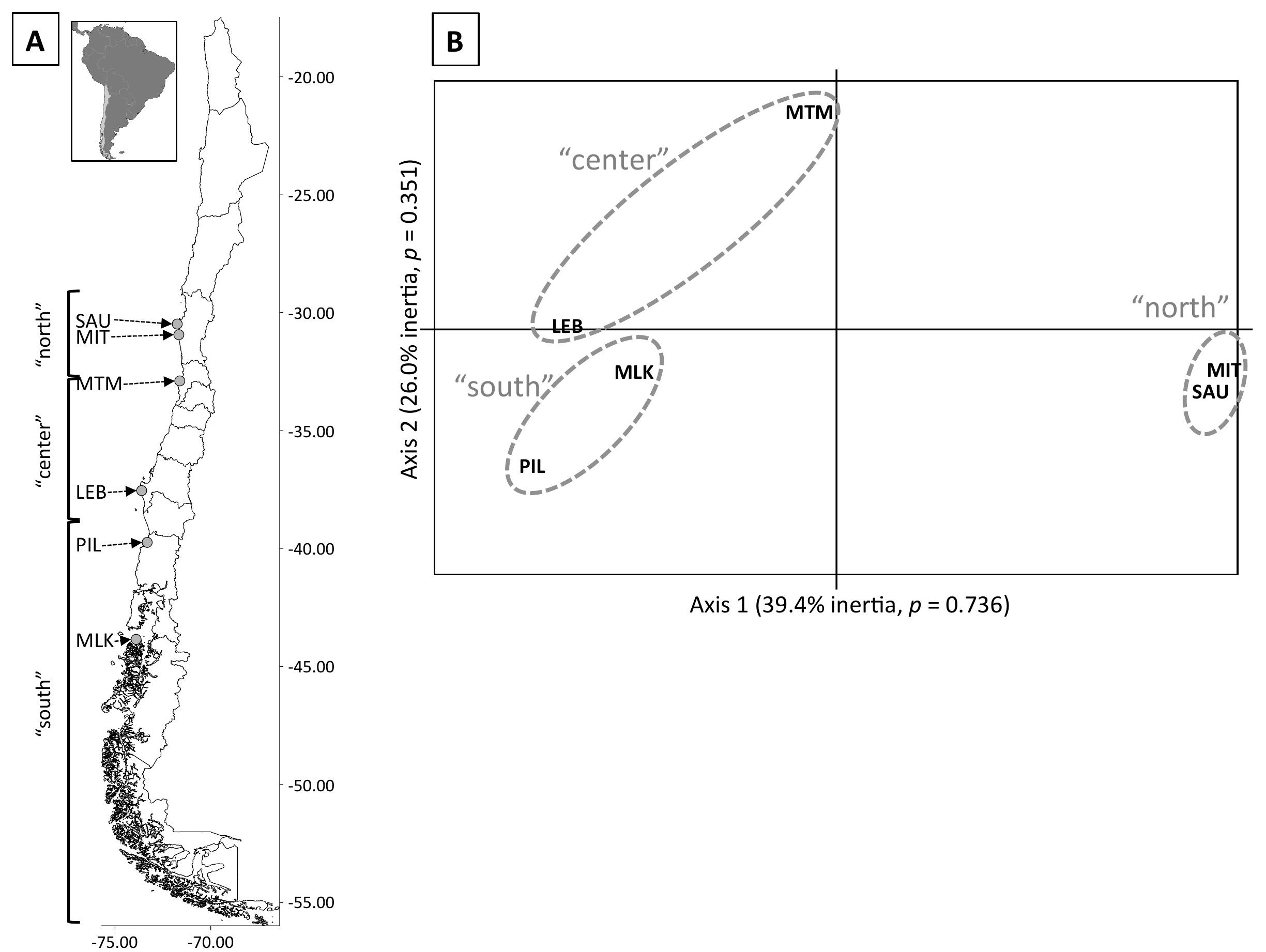




\section{Cytoplasmic lineages}

11 of the 20 runs

\begin{tabular}{|c|c|c|}
\hline North & Center & South \\
\hline
\end{tabular}

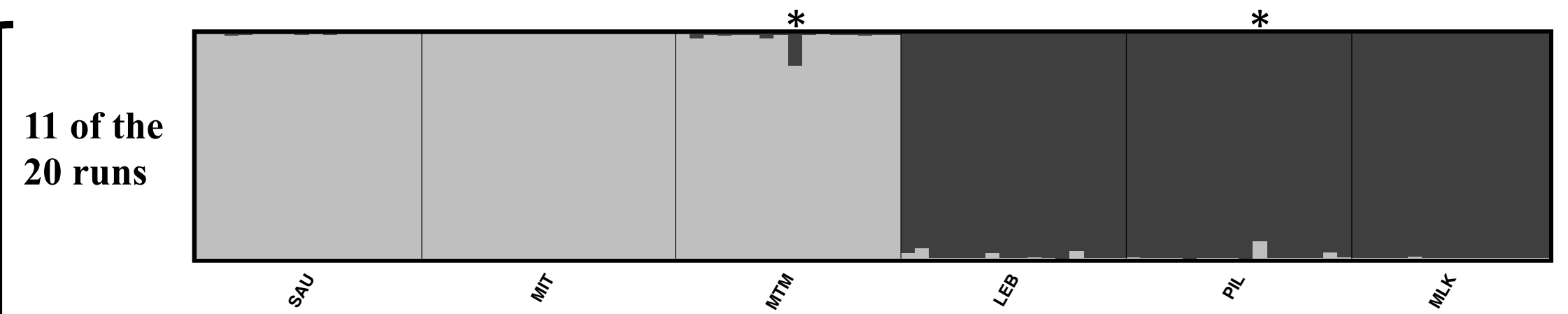

K2

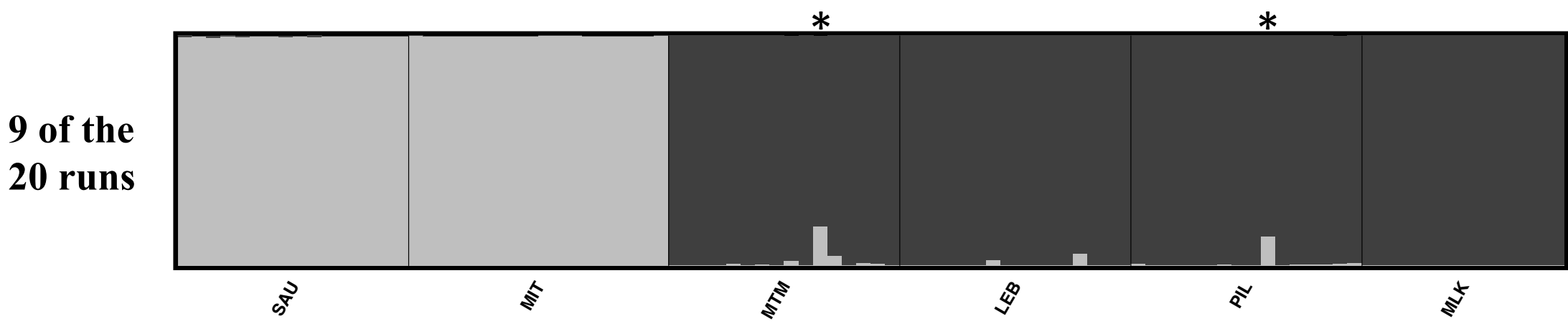

K6 [ll the

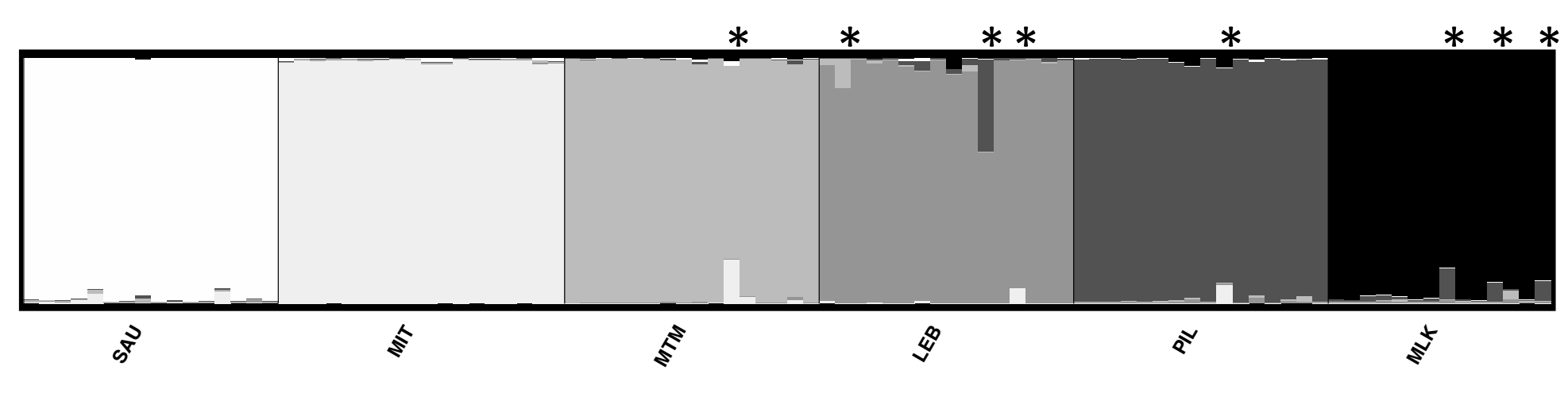


Table S1: Characteristics of 12 polymorphic microsatellite loci for the three lineages of Mazzaella laminarioides. Repeat motifs are given for every lineage for which the microsatellite sequence was encountered in the 454 nuclear contigs $(\mathrm{N}=$ northern lineage, $\mathrm{C}=$ central lineage and $\mathrm{S}=$ southern lineage). PCR conditions are given for each lineage.

\begin{tabular}{|c|c|c|c|c|c|}
\hline Locus & Primer sequence (5'-3') & Repeat motif ${ }^{t}$ & $\begin{array}{l}\text { BSA } \\
(\mu \mathrm{g} / \mu \mathrm{L})\end{array}$ & $\begin{array}{l}\mathrm{Mg} \\
(\mathrm{mM})\end{array}$ & $\mathrm{Ta}\left({ }^{\circ} \mathrm{C}\right)$ \\
\hline \multirow[t]{3}{*}{ M1_106_C462 } & F: GCAAGGGATGACCATGAC & $\mathrm{N}:$ & 0.2 & 1 & 62 \\
\hline & R: CTTGTGCCACCTCTATTCTAAGC & $\mathrm{C}:-$ & $0-0.2 *$ & $1-1.5^{*}$ & 62 \\
\hline & & $\mathrm{S}: \overline{(\mathrm{TGA}})_{12}$ & 0 & 1 & 62 \\
\hline \multirow[t]{3}{*}{ M1_106_C10 } & F: GCGTGTAGCACAGTACTTCTAC & $\mathrm{N}:(\mathrm{CA})_{10} \mathrm{AATA}(\mathrm{CA})_{4}$ & 0 & 1 & $65-67 *$ \\
\hline & R: GAAAGCACCGAAACACAGCC & $\mathrm{C}: \mathrm{CATA}(\mathrm{CA})_{9}$ & 0 & 1 & 67 \\
\hline & & S: $(\mathrm{CA})_{13} \mathrm{AATA}(\mathrm{CA})_{4}$ & 0 & 1 & $65-67 *$ \\
\hline \multirow[t]{3}{*}{ M1_39_C69 } & F: GCTGTCGAGTGTACGTTTCG & $\mathrm{N}:$ & 0.1 & 1.2 & 60 \\
\hline & R: GCCTCTGTGAAGCAAGCA & $\mathrm{C}: \overline{(\mathrm{GA}})_{9}$ & 0.1 & 1.2 & 60 \\
\hline & & $\mathrm{S}:(\mathrm{GA})_{8}$ & 0.1 & 1.2 & 60 \\
\hline \multirow[t]{3}{*}{ M1_106_C75 } & F: CGCAATCGGGAGCCATCG & $\mathrm{N}:(\mathrm{GGCTC})_{12}$ & 0 & 0.8 & 67 \\
\hline & R: CCCTATCGTGTGTTGCCACCG & $\mathrm{C}:(\mathrm{GGCTC})_{7}$ & 0 & 0.8 & 67 \\
\hline & & S: $(\text { GGCTC })_{5}$ & 0 & 0.8 & $65-67 *$ \\
\hline \multirow[t]{3}{*}{ M1_106_C32 } & F: CTGGTACAGTACCGAAGATGTC & $\mathrm{N}:(\mathrm{AC})_{12}(\mathrm{ATACACACAC})_{6}$ & 0.15 & 1.2 & 63-64* \\
\hline & R: GTTGGGTAATCGAAGAAGATGA & $\mathrm{C}:(\mathrm{AC})_{23} \mathrm{ATACTC}(\mathrm{AC})_{2}$ & 0.15 & 1.2 & 63 \\
\hline & & S: $(\mathrm{AC})_{13} \mathrm{ATACTC}(\mathrm{AC})_{2}$ & 0.15 & 1.2 & 64 \\
\hline \multirow[t]{3}{*}{ M1_106_C1748 } & F: CGTGATGTGTGTCATTTTATCCC & $\begin{array}{l}\mathrm{N}: \\
(\mathrm{CCTC})_{4} \mathrm{~N}_{44}(\mathrm{TG})_{2} \mathrm{TA}(\mathrm{TG})_{2}(\mathrm{TG} \\
\text { TGTA })_{3}\end{array}$ & 0.2 & 1 & 58 \\
\hline & R: CTGTTCCTGTTGTTCCTGCG & $\begin{array}{l}\mathrm{C}: \\
(\mathrm{CCTC})_{4} \mathrm{~N}_{44}(\mathrm{TG})_{2} \mathrm{TA}(\mathrm{TG})_{2} \mathrm{GA} \\
(\mathrm{TG})_{11}\end{array}$ & 0.05 & 1 & 61 \\
\hline & & S: $(\text { CCTC })_{4} \mathrm{~N}_{44}(\mathrm{TG})_{2} \mathrm{TA}(\mathrm{TG})_{11}$ & 0.05 & 1 & 61 \\
\hline
\end{tabular}




\begin{tabular}{|c|c|c|c|c|c|}
\hline M1_39_C1451 & $\begin{array}{l}\text { F: GGGAAAAAGCGAGCAATTTG } \\
\text { R: CTGTGCCGTCTGACATTG }\end{array}$ & 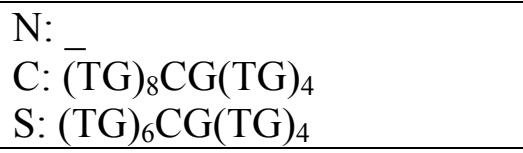 & $\begin{array}{l}0 \\
0.2 \\
0.2 \\
\end{array}$ & $\begin{array}{l}- \\
1.5 \\
1.5 \\
\end{array}$ & $\begin{array}{l}58 \\
58 \\
58 \\
\end{array}$ \\
\hline M1_39_C5118 & $\begin{array}{l}\text { F: GACTTCGCTGTCCATCCA } \\
\text { R: CAACGAATCATCCAGACGAC }\end{array}$ & $\begin{array}{l}\mathrm{N}: \\
\mathrm{C}: \overline{(\mathrm{TG}})_{7} \mathrm{TC}(\mathrm{TG})_{12} \\
\mathrm{~S}:\end{array}$ & $\begin{array}{l}0 \\
0 \\
0\end{array}$ & $\begin{array}{l}- \\
- \\
-\end{array}$ & $\begin{array}{l}64 \\
64 \\
64 \\
\end{array}$ \\
\hline M1_106_C203 & $\begin{array}{l}\text { F: CGGAGGCGACGGAGGAAG } \\
\text { R: CCTCAATTCCCTCGGTTGCTG }\end{array}$ & $\begin{array}{l}\text { N: }(\mathrm{TG})_{5} \mathrm{TA}(\mathrm{TG})_{2} \mathrm{CG}(\mathrm{TG})_{4} \\
\mathrm{C}:(\mathrm{TG})_{8} \mathrm{CG}(\mathrm{TG})_{4} \\
\text { S: }\left((\mathrm{TG})_{6} \mathrm{CG}(\mathrm{TG})_{4}\right.\end{array}$ & $\begin{array}{l}0 \\
0 \\
0\end{array}$ & $\begin{array}{l}1 \\
1 \\
1\end{array}$ & $\begin{array}{l}65 \\
66 \\
65 \\
\end{array}$ \\
\hline M1_39_C4313 & $\begin{array}{l}\text { F: ATCGTTTCAGGGCAATCACTG } \\
\text { R: TCATCCCTCCGTACCTGC }\end{array}$ & $\begin{array}{l}\mathrm{N}:(\mathrm{AG})_{6}(\mathrm{TG})_{5} \\
\mathrm{C}:(\mathrm{AG})_{6}(\mathrm{TG})_{6} \\
\text { S: }(\mathrm{AG})_{6}(\mathrm{TG})_{5}\end{array}$ & $\begin{array}{l}0 \\
0 \\
0\end{array}$ & $\begin{array}{l}- \\
- \\
-\end{array}$ & $\begin{array}{l}56-58 * \\
62 \\
62 \\
\end{array}$ \\
\hline M1_39_C37 & $\begin{array}{l}\text { F: CGGCGATGATCGACTGAGATAGAA } \\
\text { R: GATGTCCCACCAACGATTGATGG }\end{array}$ & $\begin{array}{l}\text { N: (TGTGTGTGTA })_{5}(\text { TG) })_{12} \\
\text { C: (TG) })_{24} \\
\text { S: }(\text { TG })_{14}\end{array}$ & $\begin{array}{l}0.05 \\
0.05 \\
0.05 \\
\end{array}$ & $\begin{array}{l}1 \\
1 \\
1\end{array}$ & $\begin{array}{l}65 \\
65 \\
65 \\
\end{array}$ \\
\hline M1_39_C3942 & $\begin{array}{l}\text { F: CAATGATCGTATTTACTTCGTAGCG } \\
\text { R: GCTAACCACAATACTGGCT }\end{array}$ & $\begin{array}{l}\mathrm{N}:(\mathrm{CGT})_{4} \mathrm{~N}_{12}(\mathrm{AT})_{5}(\mathrm{CT})_{2} \\
\mathrm{C}: \\
(\mathrm{CGT})_{4} \mathrm{~N}_{10}(\mathrm{AT})_{9} \mathrm{C}(\mathrm{AT})_{2}(\mathrm{CT})_{3} \\
\mathrm{~S}:\end{array}$ & $\begin{array}{l}0.2 \\
0.2 \\
0.2\end{array}$ & $\begin{array}{l}1 \\
1 \\
1\end{array}$ & $\begin{array}{l}59-61 * \\
61 \\
59-61 *\end{array}$ \\
\hline
\end{tabular}

Ta annealing temperature for the PCR program.

* When PCR conditions were different between sites from the same lineage, the range of Ta and BSA and Mg2 concentration used are given.

${ }^{E}$ A single haploid (i.e. a female gametophyte) specimen was used as the source of DNA for each three cytoplasmic lineages of $M$. laminarioides to construct the 454 libraries. Samples from Fray Jorge $\left(30^{\circ} 40^{\prime} \mathrm{S} / 71^{\circ} 42^{\prime} \mathrm{W}\right)$, Constitución $\left(35^{\circ} 19^{\prime} \mathrm{S} / 72^{\circ} 26^{\prime} \mathrm{W}\right)$ and Chiloe $\left(41^{\circ} 52^{\prime} \mathrm{S} / 71^{\circ} 01^{\prime} \mathrm{W}\right)$ were used for the northern, central and southern lineage respectively (Montecinos et al. 2012). BLAST searches between the three cytoplasmic lineages contig files were performed to identify microsatellite loci sequenced in more than one of our three 454 libraries (see Material and Methods). 
Table S2: Counts of loci for each combination of microsatellite category (di-, tri-, tetra-, and pentanucleotides) and number of perfect tandem repeat units in each Mazzaella laminarioides cytoplasmic lineage (i.e. "north", "center" and "south).

\begin{tabular}{|c|c|c|c|c|c|c|c|c|c|c|c|c|}
\hline \multirow{9}{*}{ 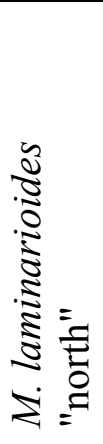 } & & $\mathrm{N}^{\circ}$ Rep. & $\mathrm{N}$ & & $\mathrm{N}^{\circ}$ Rep. & $\mathrm{N}$ & & $\mathrm{N}^{\circ}$ Rep. & $\mathrm{N}$ & & $\mathrm{N}^{\circ}$ Rep. & $\mathrm{N}$ \\
\hline & Di & 4 & 791 & Tri & 4 & 99 & Tetra & 4 & 9 & Penta & 4 & 10 \\
\hline & Di & 5 & 113 & Tri & 5 & 15 & Tetra & 5 & 0 & Penta & 5 & 0 \\
\hline & Di & 6 & 22 & Tri & 6 & 6 & Tetra & 6 & 1 & Penta & 6 & 0 \\
\hline & Di & 7 & 10 & Tri & 7 & 2 & Tetra & 7 & 0 & Penta & 7 & 0 \\
\hline & Di & 8 & 3 & Tri & 8 & 0 & Tetra & 8 & 0 & Penta & 8 & 0 \\
\hline & Di & 9 & 0 & Tri & 9 & 1 & Tetra & 9 & 0 & Penta & 9 & 0 \\
\hline & Di & 10 & 2 & Tri & 10 & 0 & Tetra & 10 & 0 & Penta & 10 & 0 \\
\hline & Di & $>10$ & 7 & Tri & $>10$ & 0 & Tetra & $>10$ & 0 & Penta & $>10$ & 0 \\
\hline
\end{tabular}

\begin{tabular}{|c|c|c|c|c|c|c|c|c|c|c|c|c|}
\hline \multirow{9}{*}{ 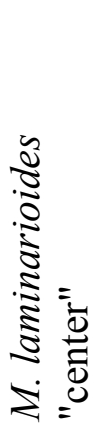 } & & $\mathrm{N}^{\circ}$ Rep. & $\mathrm{N}$ & & $\mathrm{N}^{\circ}$ Rep. & $\mathrm{N}$ & & $\mathrm{N}^{\circ}$ Rep. & $\mathrm{N}$ & & $N^{\circ}$ Rep. & $\mathrm{N}$ \\
\hline & Di & 4 & 1317 & Tri & 4 & 129 & Tetra & 4 & 10 & Penta & 4 & 11 \\
\hline & Di & 5 & 175 & Tri & 5 & 35 & Tetra & 5 & 3 & Penta & 5 & 1 \\
\hline & $\mathrm{Di}$ & 6 & 41 & Tri & 6 & 11 & Tetra & 6 & 0 & Penta & 6 & 0 \\
\hline & $\mathrm{Di}$ & 7 & 22 & Tri & 7 & 1 & Tetra & 7 & 1 & Penta & 7 & 1 \\
\hline & $\mathrm{Di}$ & 8 & 11 & Tri & 8 & 4 & Tetra & 8 & 0 & Penta & 8 & 0 \\
\hline & $\mathrm{Di}$ & 9 & 5 & Tri & 9 & 8 & Tetra & 9 & 0 & Penta & 9 & 0 \\
\hline & Di & 10 & 3 & Tri & 10 & 0 & Tetra & 10 & 0 & Penta & 10 & 0 \\
\hline & Di & $>10$ & 13 & Tri & $>10$ & 3 & Tetra & $>10$ & 0 & Penta & $>10$ & 0 \\
\hline
\end{tabular}




\begin{tabular}{|c|c|c|c|c|c|c|c|c|c|c|c|c|}
\hline \multirow{9}{*}{ 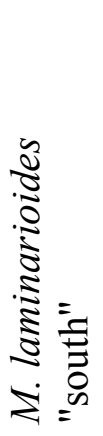 } & & $\mathrm{N}^{\circ}$ Rep. & $\mathrm{N}$ & & $\mathrm{N}^{\circ}$ Rep. & $\mathrm{N}$ & & $\mathrm{N}^{\circ}$ Rep. & $\mathrm{N}$ & & $\mathrm{N}^{\circ}$ Rep. & $\mathrm{N}$ \\
\hline & Di & 4 & 471 & Tri & 4 & 49 & Tetra & 4 & 7 & Penta & 4 & 8 \\
\hline & Di & 5 & 68 & Tri & 5 & 12 & Tetra & 5 & 1 & Penta & 5 & 0 \\
\hline & Di & 6 & 17 & Tri & 6 & 5 & Tetra & 6 & 1 & Penta & 6 & 1 \\
\hline & Di & 7 & 7 & Tri & 7 & 2 & Tetra & 7 & 1 & Penta & 7 & 0 \\
\hline & Di & 8 & 4 & Tri & 8 & 0 & Tetra & 8 & 0 & Penta & 8 & 0 \\
\hline & Di & 9 & 2 & Tri & 9 & 0 & Tetra & 9 & 0 & Penta & 9 & 0 \\
\hline & Di & 10 & 1 & Tri & 10 & 2 & Tetra & 10 & 0 & Penta & 10 & 0 \\
\hline & Di & $>10$ & 6 & Tri & $>10$ & 2 & Tetra & $>10$ & 0 & Penta & $>10$ & 0 \\
\hline
\end{tabular}


Table S3: Genetic variability within sites of Mazzaella laminarioides for the 12 microsatellite loci. Number of individuals analyzed (n); ratio of individuals successfully genotyped $(N I / n)$, with $N I=$ number of individuals successfully genotyped and $n=$ number of individuals analyzed; number of alleles per locus $(\mathrm{Na})$; expected heterozygosity $(\mathrm{He})$; observed heterozygosity $(\mathrm{Ho})$. For each single locus $F_{\text {IS }}$ estimates, significant departure from panmixia was tested by running 1,000 permutations of alleles among individuals within sites using GENETIX 4.05 software (Belkhir et al. 1996-2004). $F_{\text {IS }}$ values significantly different from zero are shown in bold. Null allele frequency (Nf) obtained with MICRO-CHECKER (Oosterhout et al. 2004; Brookfield equation 2, Brookfield 1996), locus showing a significant frequency of null alleles are shown in bold.

\begin{tabular}{|c|c|c|c|c|c|c|c|c|}
\hline \multirow[b]{2}{*}{ Loci } & \multirow{2}{*}{$\begin{array}{c}\begin{array}{c}\text { Geographic } \\
\text { origin of sampled } \\
\text { sites }\end{array} \\
\text { Site }\end{array}$} & \multicolumn{2}{|c|}{$\begin{array}{c}\text { Northern cytoplasmic } \\
\text { lineage }\end{array}$} & \multicolumn{2}{|c|}{$\begin{array}{c}\text { Central cytoplasmic } \\
\text { lineage }\end{array}$} & \multicolumn{2}{|c|}{$\begin{array}{c}\text { Southern cytoplasmic } \\
\text { lineage }\end{array}$} & \multirow[b]{2}{*}{ All } \\
\hline & & SAU & MIT & MTM & LEB & PIL & MLK & \\
\hline & $n$ & 16 & 18 & 16 & 16 & 16 & 14 & 96 \\
\hline \multirow[t]{7}{*}{ M1_106C462 } & $N I / n$ & 1 & 1 & 0.94 & 1 & 1 & 1 & 0.99 \\
\hline & $\mathrm{Na}$ & 1 & 1 & 1 & 4 & 4 & 4 & 9 \\
\hline & $\mathrm{He}$ & 0 & 0 & 0 & 0.23 & 0.23 & 0.56 & 0.76 \\
\hline & Ho & 0 & 0 & 0 & 0.13 & 0.13 & 0.43 & 0.11 \\
\hline & $F_{\text {IS }}$ & - & - & - & 0.48 & 0.48 & 0.27 & \\
\hline & $p$ & - & - & - & 0.03 & 0.04 & 0.172 & \\
\hline & $N f$ & & - & - & 0.08 & 0.08 & 0.09 & \\
\hline \multirow[t]{3}{*}{ M1_106C10 } & $N I / n$ & 1 & 1 & 1 & 1 & 1 & 1 & 1 \\
\hline & $N a$ & 5 & 4 & 3 & 3 & 4 & 3 & 12 \\
\hline & $\mathrm{He}$ & 0.33 & 0.7 & 0.23 & 0.53 & 0.48 & 0.46 & 0.81 \\
\hline
\end{tabular}




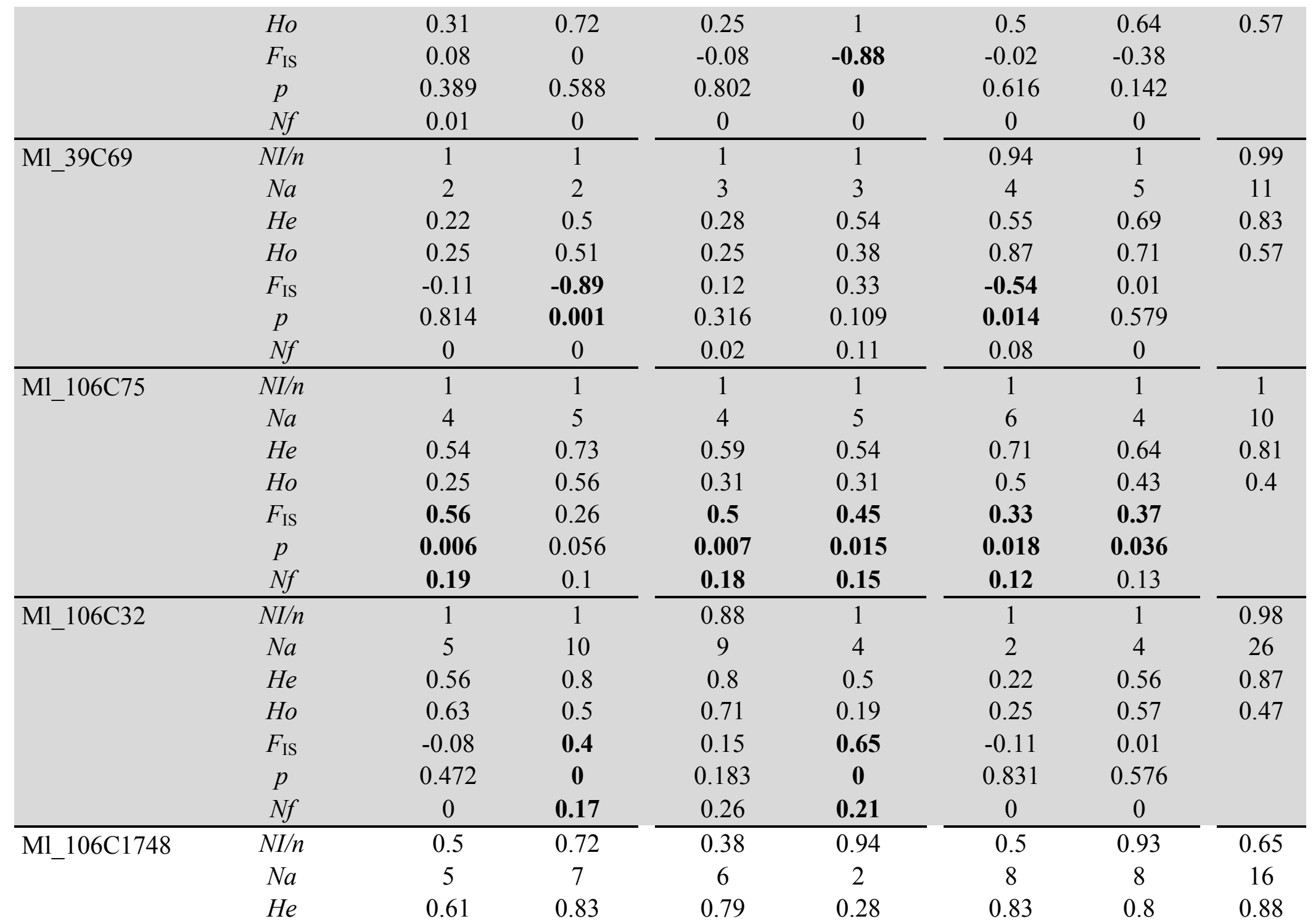




\begin{tabular}{|c|c|c|c|c|c|c|c|c|}
\hline & Ho & 0.38 & 0.69 & 0.5 & 0.33 & 0.75 & 0.77 & 0.57 \\
\hline & $F_{\text {IS }}$ & 0.44 & 0.21 & 0.44 & -0.17 & 0.16 & 0.07 & \\
\hline & $p$ & 0.055 & 0.083 & 0.03 & 0.653 & 0.226 & 0.437 & \\
\hline & $N f$ & 0.72 & 0.45 & 0.82 & 0.19 & 0.66 & 0.16 & \\
\hline \multirow[t]{7}{*}{ Ml_39C1451 } & $N I / n$ & 0.94 & 1 & 1 & 1 & 1 & 1 & 0.99 \\
\hline & $N a$ & 3 & 2 & 4 & 2 & 2 & 3 & 4 \\
\hline & $\mathrm{He}$ & 0.18 & 0.28 & 0.56 & 0.31 & 0.43 & 0.52 & 0.66 \\
\hline & Ho & 0.07 & 0.22 & 0.57 & 0.38 & 0.63 & 0.64 & 0.32 \\
\hline & $F_{\text {IS }}$ & 0.66 & 0.23 & 1 & -0.2 & -0.43 & -0.21 & \\
\hline & $p$ & 0.033 & 0.396 & $\mathbf{0}$ & 0.582 & 0.152 & 0.28 & \\
\hline & $N f$ & 0.28 & 0.04 & 0.36 & 0 & 0 & 0 & \\
\hline \multirow[t]{7}{*}{ M1_39C5118 } & $N I / n$ & 1 & 1 & 1 & 1 & 1 & 1 & 1 \\
\hline & $N a$ & 1 & 3 & 4 & 8 & 3 & 2 & 10 \\
\hline & $\mathrm{He}$ & 0 & 0.45 & 0.59 & 0.64 & 0.23 & 0.5 & 0.72 \\
\hline & Ho & 0 & 0.47 & 0.06 & 0.63 & 0.25 & 0.5 & 0.3 \\
\hline & $F_{\text {IS }}$ & - & 0.17 & 0.9 & 0.05 & -0.08 & 0.03 & \\
\hline & $p$ & - & 0.304 & $\mathbf{0}$ & 0.488 & 0.8 & 0.625 & \\
\hline & $N f$ & & 0.04 & 0.33 & 0.01 & 0 & 0 & \\
\hline \multirow[t]{7}{*}{ Ml_106C203 } & $N I / n$ & 1 & 1 & 1 & 1 & 1 & 1 & 1 \\
\hline & $\mathrm{Na}$ & 1 & 1 & 2 & 2 & 1 & 1 & 2 \\
\hline & $\mathrm{He}$ & 0 & 0 & 0.06 & 0.26 & 0 & 0 & 0.47 \\
\hline & Ho & 0 & 0 & 0.06 & 0.31 & 0 & 0 & 0.06 \\
\hline & $F_{\text {IS }}$ & - & - & 0 & -0.15 & - & - & \\
\hline & $p$ & - & - & 0.8 & 0.682 & _ & _ & \\
\hline & $N f$ & . & - & 0 & 0 & . & . & \\
\hline \multirow{3}{*}{ Ml_39C4313 } & $N I / n$ & 1 & 1 & 0.94 & 1 & 1 & 1 & 0.99 \\
\hline & $N a$ & 5 & 4 & 3 & 2 & 1 & 2 & 6 \\
\hline & $\mathrm{He}$ & 0.6 & 0.6 & 0.29 & 0.45 & 0 & 0.5 & 0.59 \\
\hline
\end{tabular}




\begin{tabular}{|c|c|c|c|c|c|c|c|c|}
\hline & Ho & 0.69 & 0.28 & 0.33 & 0.69 & 0 & 1 & 0.48 \\
\hline & $F_{\text {IS }}$ & -0.11 & 0.56 & -0.13 & -0.5 & - & -1 & \\
\hline & $p$ & 0.396 & $\mathbf{0}$ & 0.685 & 0.075 & - & $\mathbf{0}$ & \\
\hline & $N f$ & 0 & 0.2 & 0.19 & 0 & & 0 & \\
\hline \multirow[t]{7}{*}{ M1_39C37 } & $N I / n$ & 1 & 1 & 0.88 & 1 & 1 & 0.93 & 0.97 \\
\hline & $N a$ & 4 & 9 & 10 & 4 & 3 & 4 & 23 \\
\hline & $\mathrm{He}$ & 0.56 & 0.8 & 0.84 & 0.53 & 0.27 & 0.7 & 0.86 \\
\hline & Ho & 0.44 & 0.44 & 0.64 & 0.25 & 0.31 & 0.31 & 0.4 \\
\hline & $F_{\text {IS }}$ & 0.25 & 0.47 & 0.27 & 0.55 & -0.12 & 0.58 & \\
\hline & $p$ & 0.186 & $\mathbf{0}$ & 0.012 & 0.05 & 0.675 & $\mathbf{0}$ & \\
\hline & $N f$ & 0.08 & 0.2 & 0.3 & 0.18 & 0 & 0.34 & \\
\hline \multirow[t]{7}{*}{ M1_106C3942 } & $N I / n$ & 1 & 1 & 1 & 1 & 0.94 & 1 & 0.99 \\
\hline & $N a$ & 2 & 2 & 1 & 4 & 2 & 2 & 5 \\
\hline & $\mathrm{He}$ & 0.22 & 0.11 & 0 & 0.61 & 0.28 & 0.5 & 0.63 \\
\hline & Ho & 0.13 & 0.11 & 0 & 0.94 & 0.33 & 1 & 0.4 \\
\hline & $F_{\text {IS }}$ & 0.46 & -0.03 & - & -0.52 & -0.17 & -1 & \\
\hline & $p$ & 0.009 & 0.978 & - & 0.009 & 0.679 & 0 & \\
\hline & $N f$ & 0.08 & 0 & & 0 & 0.19 & 0 & \\
\hline
\end{tabular}


Table S4: Pairwise multilocus estimates of $F_{\mathrm{ST}}(\theta)$ (Weir and Cockerham 1984). Values above the diagonal correspond to estimates calculated using the uncorrected 9 loci dataset while the values below the diagonal correspond to estimates calculated using the 9 loci dataset corrected for null alleles using Brookfield equation 2 (Brookfield 1996) implemented in MICRO-CHECKER (Oosterhout et al. 2004). Regardless of the dataset tested, all estimates were associated with significant values of $p$, as assessed by running 1000 permutations using GENETIX 4.05 (Belkhir et al. 1996-2004).

\begin{tabular}{|c|c|c|c|c|c|c|}
\hline & SAU & MIT & MTM & LEB & PIL & MLK \\
\hline SAU & - & 0.398 & 0.563 & 0.549 & 0.581 & 0.482 \\
\hline MIT & 0.389 & - & 0.505 & 0.469 & 0.537 & 0.431 \\
\hline MTM & 0.562 & 0.494 & - & 0.434 & 0.574 & 0.402 \\
\hline LEB & 0.542 & 0.457 & 0.420 & - & 0.358 & 0.318 \\
\hline PIL & 0.571 & 0.535 & 0.571 & 0.350 & - & 0.253 \\
\hline MLK & 0.479 & 0.431 & 0.389 & 0.312 & 0.249 & - \\
\hline
\end{tabular}




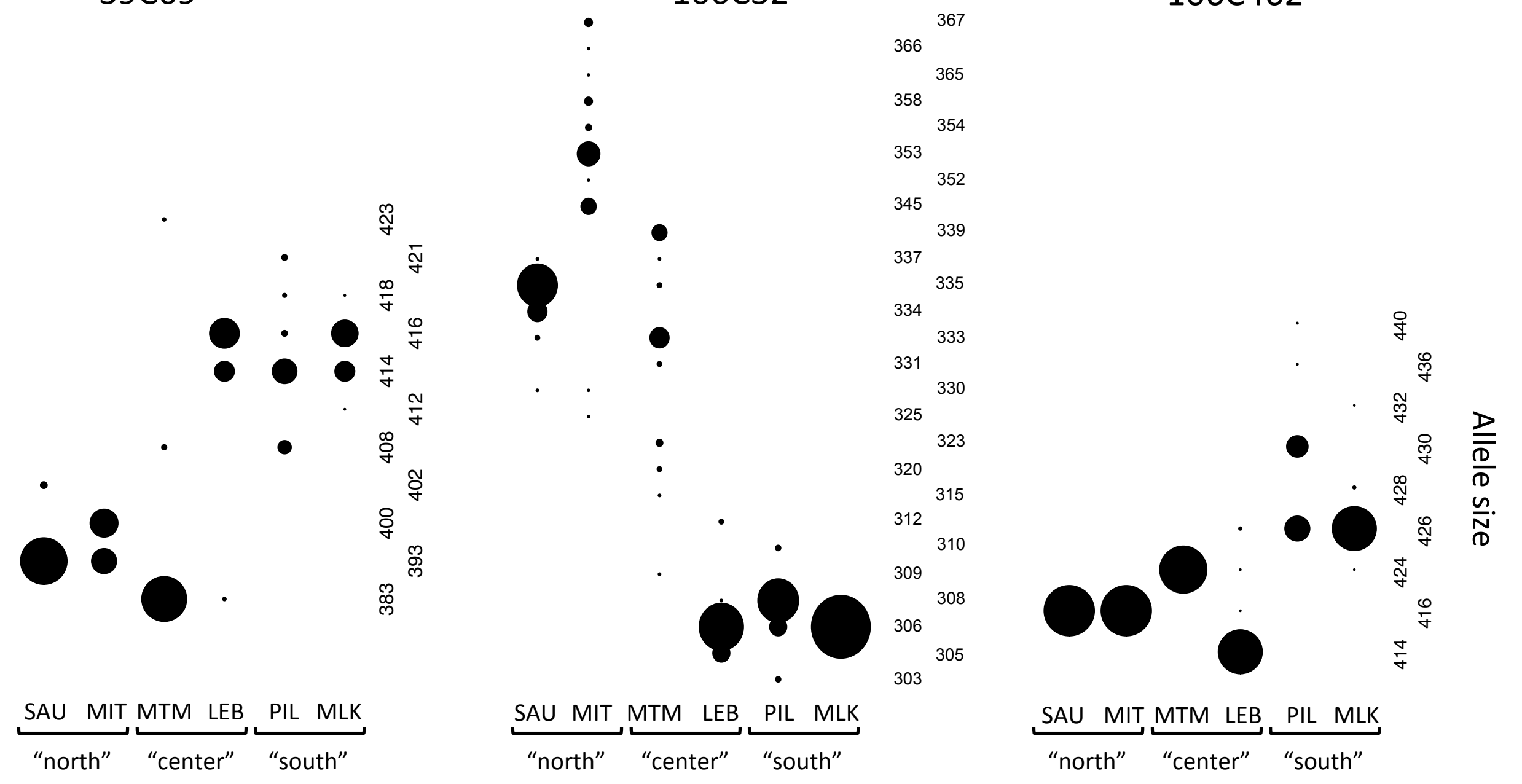

Figure S1: Allele frequency distributions for the nine microsatellite loci observed in each of the six study sites. Sites on the $x$-axis are ranged from north to south. Numbers on the $y$-axis are allele sizes in base pairs for each locus. Each circle indicates presence of corresponding allele; diameter of circle represents frequency of that allele in the site. Cytoplasmic lineages (M. laminarioides "north", "center" and "south") are noted below the site codes. 


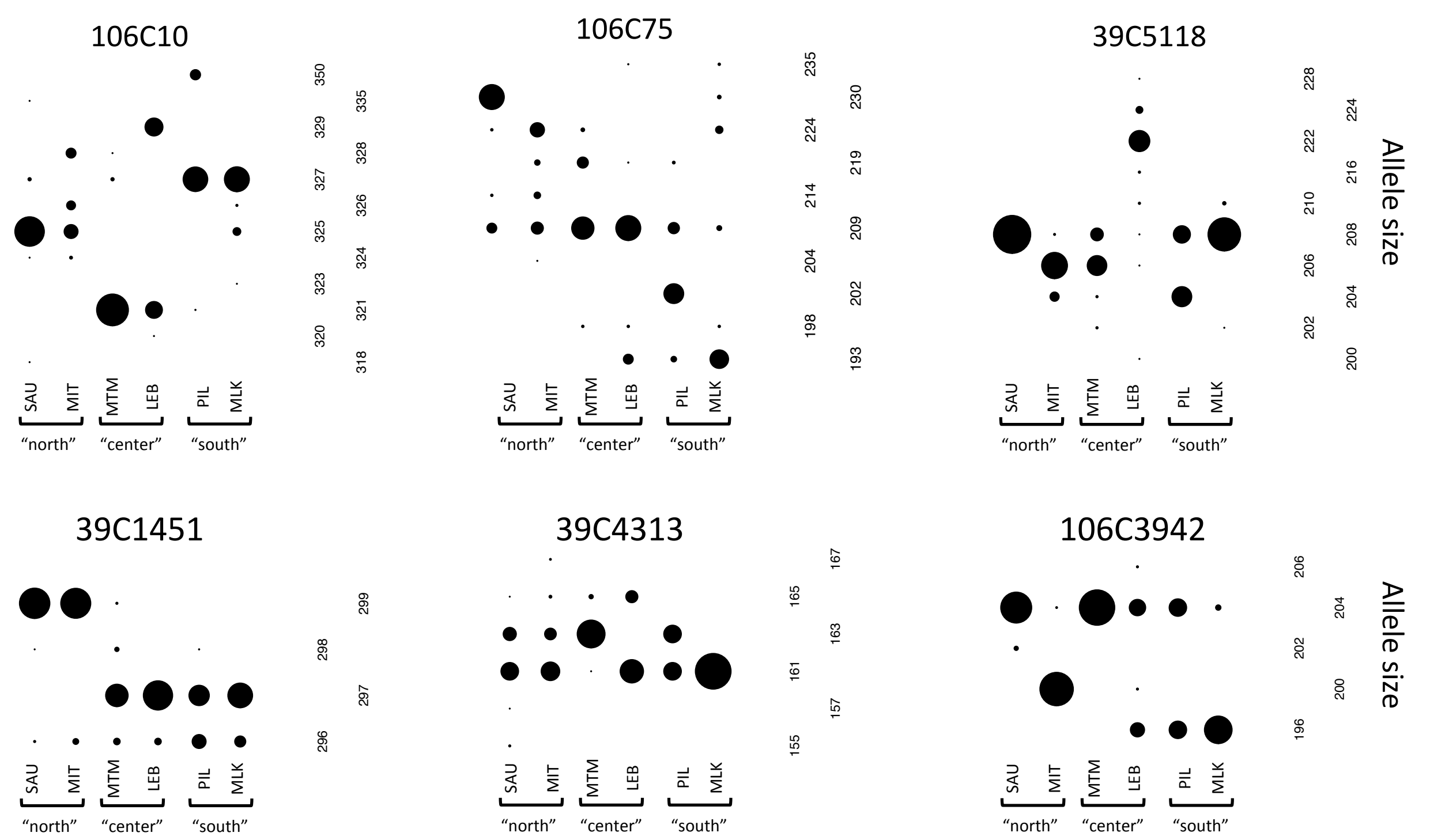

\footnotetext{
Figure S1: Continued from previous page
} 
Figure S2: The posterior probability of the data given $\mathrm{K}$ (noted $\mathrm{P}(\mathrm{X} \mid \mathrm{K})$, dark circle) and $\Delta \mathrm{K}$ (white circle) results are given for $\mathrm{K}=1$ to 7 using the results of the Bayesian analysis obtained with STRUCTURE.

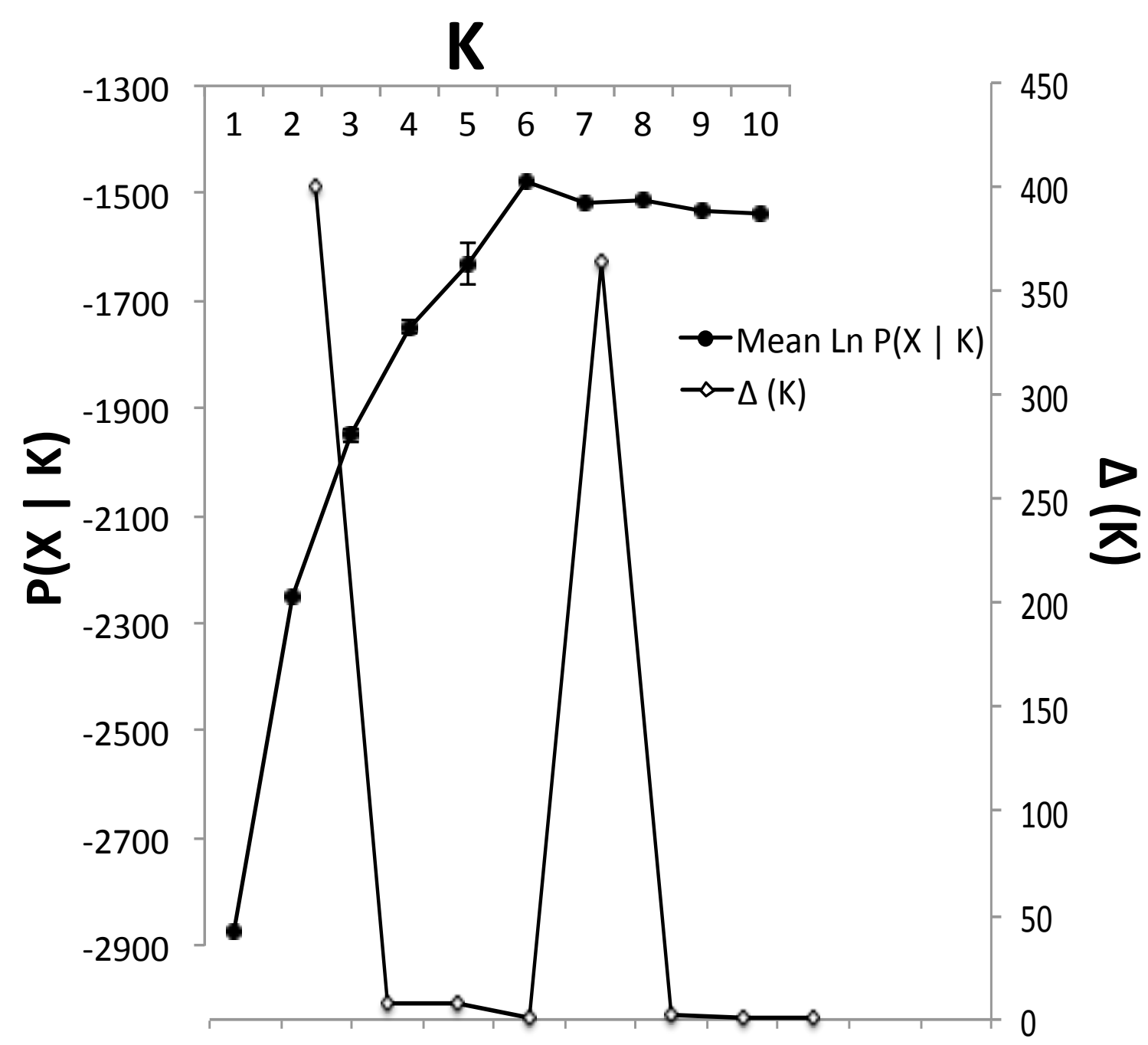


Figure S3: Bayesian analysis using INSTRUCT for the six study sites of Mazzaella laminarioides. A)

Estimated Deviance Information Criterion (DIC) for values of $\mathrm{K}=1$ to $7 . \mathrm{B}$ ) Results of the genetic clustering of the 96 Mazzaella laminarioides samples assuming K6. Each vertical bar represents a different individual. Each color represents the proportion of individual genome assigned to each genetic group and * indicates individuals for which a secondary cluster represents more than $5 \%$ of the genome (i.e. admixed individuals). Individuals are ordered from north to south.

\section{INSTRUCT RESULTS}

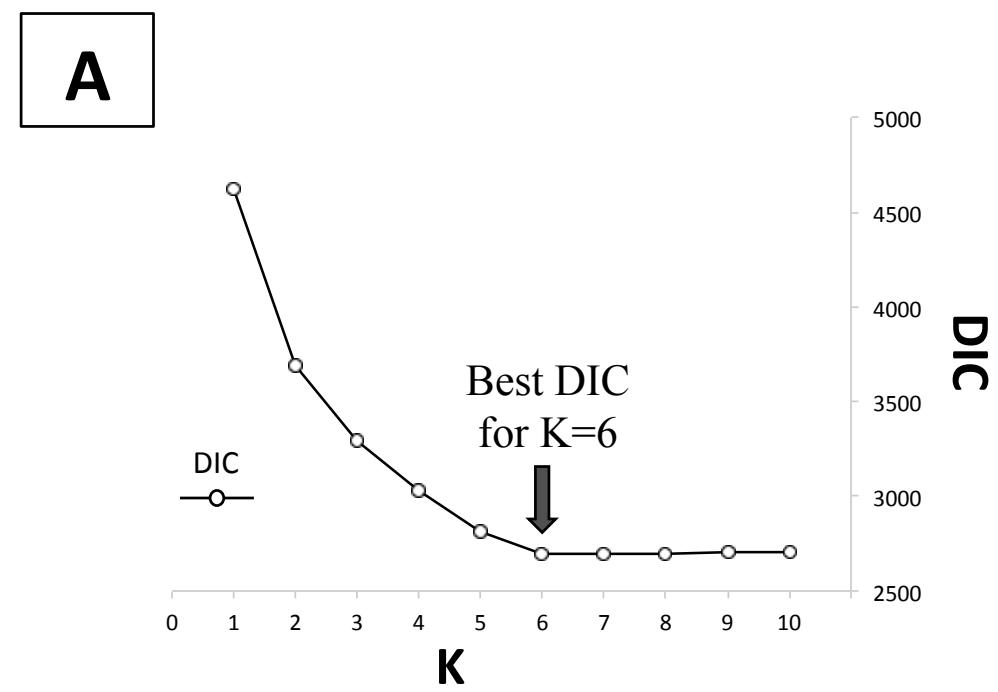

B

Cytoplasmic lineages

\begin{tabular}{|l|l|l|}
\hline North & Center & South \\
\hline
\end{tabular}

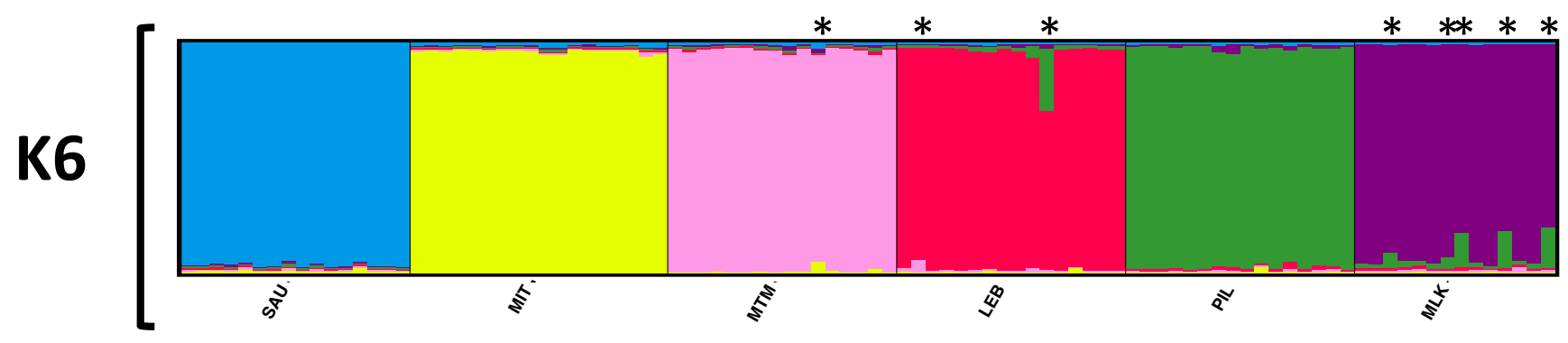

